\title{
Genome-wide identification and characterization of aquaporin gene family in Beta vulgaris
}

\author{
Weilong Kong ${ }^{1}$, Shaozong Yang ${ }^{1}$, Yulu Wang ${ }^{1}$, Mohammed Bendahmane ${ }^{2}$ ， Xiaopeng Fu ${ }^{\text {Corresp. } 1}$ \\ ${ }^{1}$ College of Horticulture and Forestry Sciences, Huazhong Agricultural University, Key Laboratory of Horticultural Plant Biology, Ministry of Education, \\ Wuhan, Hubei, China \\ 2 INRA-CNRS-Lyon1-ENS, Laboratoire Reproduction et Developpement des Plantes, Ecole Normale Supérieure Lyon, France \\ Corresponding Author: Xiaopeng Fu \\ Email address: fuxiaopeng@mail.hzau.edu.cn
}

Aquaporins (AQPs) are essential channel proteins that execute multi-functions throughout plant growth and development, including water transport, uncharged solutes uptake, stress response, etc. Here, we report the first genome-wide identification and characterization $A Q P(B \vee A Q P)$ genes in sugar beet (Beta vulgaris), an important crop widely cultivated for feed, for sugar production and for bioethanol production. 28 sugar beet $A Q P S$ ( $B V A Q P S$ ) were identified and assigned into five subfamilies based on phylogenetic analyses: 7 of plasma membrane (PIPs), 8 of tonoplast (TIPs), 9 of NOD26-like (NIPs), 3 of small basic (SIPs), and 1 of $x$-intrinsic proteins (XIPs). BVAQP genes unevenly mapped on all chromosomes, except on chromosome 4 . Gene structure and motifs analyses revealed that $B V A Q P$ have conserved exon-intron organization and that they exhibit conserved motifs within each subfamily. Prediction of BvAQPs functions, based on key protein domains conservation, showed a remarkable difference in substrate specificity among the five subfamilies. Analyses of BVAQPs expression, by mean of RNA-seq, in different plant organs and in response to various abiotic stresses revealed that they were ubiquitously expressed and that their expression was induced by heat and salt stresses. These results provide a reference base to address further the function of sugar beet aquaporins and to explore future applications for plants growth and development improvements as well as in response to environmental stresses. 
1 Genome-wide identification and characterization of aquaporin gene family in Beta vulgaris

2 Author: Weilong KONG1, Shaozong YANG ${ }^{1}$, Yulu WANG ${ }^{1}$, Mohammed BENDAHMANE²,

3 Xiaopeng $\mathrm{FU}^{1}$

4 Affiliations: ${ }^{1}$ Key Laboratory of Horticultural Plant Biology, Ministry of Education, College of

5 Horticulture and Forestry Sciences, Hua zhong Agricultural University, Hubei, Wuhan, China; ${ }^{2}$

6 Laboratoire Reproduction et Developpement des Plantes, INRA-CNRS-Lyon1-ENS, Ecole

7 Normale Supérieure Lyon France.

8 Corresponding Author:

9 Name: Xiaopeng Fu

10 E-mail: fuxiaopeng@mail.hzau.edu.cn

\section{Abstract}

Aquaporins (AQPs) are essential channel proteins that execute multi-functions throughout plant growth and development, including water transport, uncharged solutes uptake, stress response, etc. Here, we report the first genome-wide identification and characterization $A Q P(B v A Q P)$ genes in sugar beet (Beta vulgaris), an important crop widely cultivated for feed, for sugar production and for bioethanol production. 28 sugar beet $A Q P s$ (BvAQPs) were identified and assigned into five subfamilies based on phylogenetic analyses: 7 of plasma membrane (PIPs), 8 of tonoplast (TIPs), 9 of NOD26-like (NIPs), 3 of small basic (SIPs), and 1 of x-intrinsic proteins (XIPs). BvAQP genes unevenly mapped on all chromosomes, except on chromosome 4. Gene structure and motifs analyses revealed that $B v A Q P$ have conserved exon-intron organization and that they exhibit conserved motifs within each subfamily. Prediction of BvAQPs functions, based on key protein domains conservation, showed a remarkable difference in substrate specificity among the five subfamilies. Analyses of $B v A Q P s$ expression, by mean of RNA-seq, in different plant organs and in response to various abiotic stresses revealed that they were ubiquitously expressed and that their expression was induced by heat and salt stresses. These results provide a reference base to address further the function of sugar beet aquaporins and to explore future 
environmental stresses.

\section{Introduction:}

AQPs are known to facilitate water transport and other small nutrients through cell membranes (Maurel et al. 2009; Maurel et al. 2008). Since the discovery of the first aquaporin (AQP1) in mammals, AQPs were identified in many microorganisms, plants and animals (Gomes et al. 2009).

Plants aquaporins family is complex, and is composed of large number genes. For example there are 35 AQPs in Arabidopsis thaliana, 31 in Zea mays, 34 in Oryza sativa, 55 in Populus trichocarpa and 66 AQPs in Glycine max (Johanson \& Kjellbom 2001; Nguyen et al. 2013; Chaumont et al. 2001; Gupta \& R 2009; Zhang et al. 2013). In Plants AQPs paly major roles in water and solute transport, in maintaining water homeostasis and in the response to environment stresses. AQPs roles in glycerol, urea, boric acid, silicic acid, $\mathrm{H}_{2} \mathrm{O}_{2}, \mathrm{NH}_{3}$ and $\mathrm{CO}_{2}$ transport through cell membranes, was reported to be important for cytoplasm homeostasis, seed germination, embolism recovery, petal and leaf movement, guard cells closure, fruit ripening and maintenance of cell turgor under various stresses (Fitzpatrick \& Reid 2009; Maurel et al. 2009; Maurel et al. 2008; Mitani-Ueno et al. 2011; Heinen \& Chaumont 2009; Maurel et al. 2008; Prado \& Maurel 2013; Uehlein \& Kaldenhoff 2008; Wudick \& Maurel 2009).

To date, AQPs are recognized into seven subfamilies: PIPs, TIPs, NIPs, SIPs, XIPs, GIPs, and HIPs (Anderberg et al. 2012; Danielson \& Johanson 2008). Green plants usually contain four subfamilies: PIPs, TIPs, NIPs, and SIPs. However, members of XIPs subfamily were also found in some dicots, such as Solanum lycopersicum (Venkatesh et al. 2013), Populus trichocarpa (Gupta \& Sankararamakrishnan 2009) and Glycine max (Cheng et al. 2013), but were absent in Brassicaceae and monocots (Danielson \& Johanson 2008). GIPs and HIPs subfamilies were reported in moss (Physcomitrella patens) and fern (Selaginella moellendorffii).

AQPs are highly conserved in all living organisms, consisting of six transmembrane domains (TM1-TM6) connected by five loops (LA-LE). NPA motifs, the ar/R selectivity and Froger's 
55

56

57

position are critical for AQPs functions. Two NPA motifs (Asn-Pro-Ala) are located on LB and LE, forming a central aqueous pore in the middle of the lipid bilayer involved in proton exclusion and substrate selectivity (Bansal \& Sankararamakrishnan 2007). The ar/R selectivity is formed by four resides from TM2 (H2), TM5 (H5), LE (LE1 and LE2) and acts as a sizeexclusion barrier (Hove \& Bhave 2011; Mitani-Ueno et al. 2011). Froger's position consists of five conserved resides (P1-P5) and discriminations between AQP-type and GIP-type AQPs (Froger et al. 1998). Nine specificity-determining positions for non-aqua substrates (i.e. urea, boric, acid, silicic, ammonia, carbon dioxide and hydrogen peroxide $\left.\left(\mathrm{H}_{2} \mathrm{O}_{2}\right)\right)$ were also proposed based on a comprehensive analysis of functionally characterized AQPs (Hove \& Bhave 2011).

Sugar beet belongs to Caryophyllales, which lays on basal taxa of core dicots. It is an important crop in temperate climates region and provides nearly $30 \%$ of the world's annual sugar production (Dohm et al. 2014). It is also used as a source for animal feed and for bioethanol production.

To date, little is known about AQPs in sugar beet and in Caryophyllales. So far, only information on 26 AQPs, grouped in five subfamilies (8 PIPs, 11 TIPs, 4 NIPs, 2 SIPs and 1 XIP), was reported in carnation (Morita et al. 2017). More information on AQPs in Caryophyllales plants is therefore required to help understand their function and evolution.

Here we used the available high-quality genome sequence (Dohm et al. 2014) and RNA-seq datasets (Minoche et al. 2015) of sugar beet to identify and characterized the expression of BvAQPs. We report the distribution of BvAQPs on chromosomes, phylogeny analysis, gene structure, subcellular location, conserved resides and conserved elements. We propose putative functions of sugar beet AQPs based on their detailed genes expression patterns analysis by the mean of RNA-seq.

\section{Methods}

\section{Identification and distribution of $A Q P$ genes in sugar beet}

BvAQPs were identified by HMM (Hidden Markov Model) and BLAST homology search. The 
82 sugar beet predicted proteome was collected using the sugar beet genome RefBeet-1.2 83 (http://bvseq.molgen.mpg.de/Genome/Download/index.shtml). The Hidden Markov model 84 (HMM) of the MIP domain (PF00230) was downloaded from the Sanger database 85 (http://pfam.xfam.org/family/PF00230). PF00230 was then used to query the predicted Sugar

86

87 beet proteome using HMMER 3.0 software (http://hmmer.org/). 35 Arabidopsis AtAQPs were download from TAIR Database (https://www.arabidopsis.org/browse/genefamily/ Aquaporins.jsp) and then used to search BvAQPs with BLASTp tool using NCBI sugar beet genome (https://www.ncbi.nlm.nih.gov/genome/?term=Beta+vulgaris) and sugar beet genome (http://www.genomforschung.uni-bielefeld.de/en/projects/annobeet) (Baranwal et al. 2016) with cut-off E-value of $\mathrm{e}^{-5}$. All no-redundant gene sequences were analyzed by SMART (http://smart.embl-heidelberg.de/) and Pfam (http://pfam.xfam.org/search/sequence). Sequences encoding complete MIP domain and two NPA motifs were considered as putative AQP genes. Additionally, the molecular weight (MW) and isoelectric point (PI) of BvAQPs were calculated by ExPASy (http://www.expasy.org/); transmembrane helical domains (TMHs) were assessed by TMHMM Sever v.2.0 (http://www.cbs.dtu.dk/services/TMHMM/); the subcellular localization of BvAQPs were predicted using Plant-mPLoc (http://www.csbio.sjtu. edu.cn/bioinf/plant-multi/) and WolF PSORT (http://www.genscript.com/wolf-psort.html). Position of the $A Q P$ genes on the sugar beet chromosomes were identified based on position information from the sugar beet genome database and the distribution graph of $A Q P$ genes was drawn by MapInspect software (http://mapinspect.software.informer.com/).

\section{Phylogenetic analyses and sequence alignments}

BvAQPs were aligned with AtAQPs from Arabidopsis (https://www.arabidopsis.org/) DcAQPs from Dianthus caryophyllus (Morita et al. 2017; http://carnation.kazusa.or.jp/ blast.html), by using Clustal W. Phylogenetic tree was built by MEGA6.0 (http://www.megasoftware.net/history.php) using the neighbor-joining (NJ) method, with 1000 times bootstrap replicates. BvAQPs were named based on their sequence homology and phylogenetic analyses. Greek letters $(\alpha, \beta)$ were used to denote the transcripts derived from the 
109

110

111

112

113

114

115

116

117

118

119

120

121

122

123

124

125

126

127

128

129

130

131

132

133

134

135

same gene.

BvAQPs and two S. tuberosum AQPs (Venkatesh et al. 2013) were aligned by DNAMAN (http://dnaman.software.informer.com/) with default parameters. Two NPA motifs, ar/R selectivity filter and Froger's position were inferred from the multiple sequence alignment result from DNAMAN. Specificity-determining positions (SDP1-SDP9) from alignments with the structure resolved Spinacia oleracea PIP2;1 and functionally characterized AQPs as being collected by Hove and Bhave (Hove \& Bhave 2011).

\section{Exon-intron structure, tandem duplication events and conserved motifs distribution}

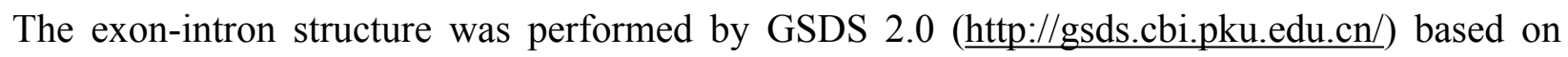
genes coding sequences and on the annotated genome. Tandem duplication events were analyzed in BvAQP genes (Gu et al. 2002; He et al. 2012). Conserved motifs of BvAQPs were analyzed by MEME suit (http://meme-suite.org/), and the parameters were set as follows: maximum number is 10 , other default parameters.

\section{Expression analysis of sugar beet AQP genes}

RNA-seq data (SRX287608-287615) were collected from NCBI and used to analyse the expression profiles of AQP genes in different organs and tissues (seedling, root, leaf, inflorescence and seed). Salt and heat tolerance is largely dependent on the plant ability to maintain optimal water status in leaves. The adjustment of water relation under salinity involves changes in the transcriptional activity of genes encoding AQPs. Expression variations of $B v A Q P S$ in young leaf under salt or heat stress, were analyzed using RNA-seq data (SRX647324; SRX647712; SRX647714) (Minoche et al. 2015).

HISAT2 was used to align raw reads to the reference genome, and StringTie was used to calculate gene expression (Stracke et al. 2014). The heat map for tissue-specific expression profile was generated based on the $\log _{2}{ }^{R P K M}$ values for each gene in all the tissue samples using $\mathrm{R}$ package (Gentleman et al. 2004). Stress inducible profile of $B v A Q P$ genes in young leaf, 
136 137 shown in terms of $\log _{2}$ fold (Venkatesh et al. 2013).

138

139

140

141

142

143

144

145

146

147

\section{Results} and SIP1;1 $\beta$. and BvTIP2;2, BvNIP7;1 and BvXIP1;1 had 7 TMHs.

RPKM values were normalized to untreated controls, and expression fold changes in genes were

\section{Identification, classification and properties of $B v A Q P$ genes in sugar beet}

In total 28 non-redundant genes were assigned as putative $A Q P \mathrm{~s}$. The predicted protein sequence of all AQPs ranged from 236 to 327 amino acids (Table 1. Sequence cluster analysis of AQPs from A. thaliana, D. caryophyllus and sugar beet permitted to group them into five subfamilies: 7 PIPs, 8 TIPs, 9 NIPs, 3 SIPs and 1 XIPs (Fig 1). PIPs subfamily was further divided into 3 PIP1s and 4 PIP2s subgroups. The TIPs subfamily included 4 subgroups (3 TIP1s, 2 TIPs, 1 TIP3, 1 TIP4, 1 TIP5). NIPs subfamily was dived into 5 subgroups (1 NIP1, 2 NIP4s, 2 NIP5s, 3 NIP6s, 1 NIP7). SIPs subfamily divided into 2 subgroups (2 SIP1s, 1 SIP2). Only one member (XIP1) composed XIPs subfamily. A pair of transcripts were found in SIP1 subgroup, named BvSIP1;1 $\alpha$

Bioinformatics analysis revealed that MW of BvAQPs ranged from 25.09 to $35.08 \mathrm{kDa}$ with a $\mathrm{pI}$ between 4.7 and 9.74 (Table 1). TIPs and SIPs were smaller $(<27 \mathrm{kDa})$ than PIPs, NIPs and XIPs. TIPs were acidic while the other subfamilies were alkaline. Great majority of AQPs were predicted have 6 TMHs, while BvPIP1;1, BvTIP3;1, BvSIP1;1 $\alpha$ and BvSIP2;1 had only 5 TMHs 


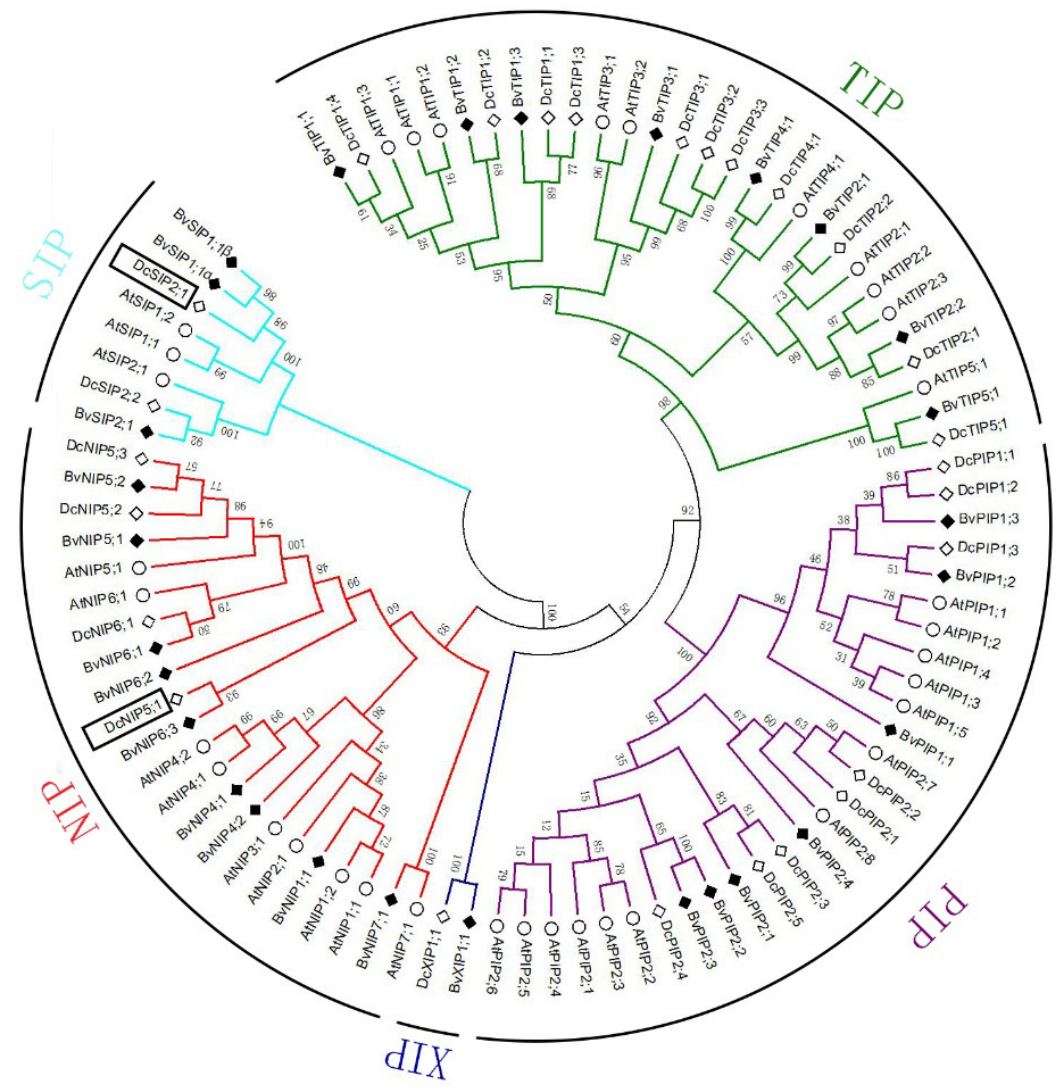

156

157

158

159

160

161

162

163

164

165

166

167

Fig 1 Multiple alignments and phylogenetic analysis of BvAQPs A. thaliana AtAQPs and D. caryophyllus DcAQPs.

Multiple alignments were performed using the default parameter of Clustal W. Phylogenetic dendrogram was generated by MEGA 6 using neighbor-joining (NJ) method with 1000 bootstrap replicates.

Table 1 Identification of $B v A Q P$ genes using sugar beet genome data. 


\begin{tabular}{|c|c|c|c|c|c|c|c|c|c|}
\hline Family & Gene & Gene ID & Gene code & $\begin{array}{l}\text { Protein length } \\
\text { (aa) }\end{array}$ & MW (kDa) & pI & TMHs & Plant-mPLoc & WoLF PSORT \\
\hline \multirow{7}{*}{ PIP } & BvPIP1;1 & fpur & Bv1g004510_fpur.t1 & 289 & 31.1 & 8.84 & 5 & plas & cyto \\
\hline & BvPIP1;2 & $\operatorname{shpz}$ & Bv1g004520_shpz.t1 & 285 & 30.67 & 9.05 & 6 & plas & plas \\
\hline & BvPIP 1;3 & gqok & Bv2g024120_gqok.t1 & 286 & 30.74 & 9.14 & 6 & plas & plas \\
\hline & BvPIP2;1 & cqnr & Bv7g163390_cqnr.t1 & 284 & 30.32 & 8.31 & 6 & plas & plas \\
\hline & BvPIP $2 ; 2$ & ixem & Bv9g210030_ixem.t1 & 288 & 31.09 & 7.08 & 6 & plas & plas \\
\hline & BvPIP $2 ; 3$ & yige & $\begin{array}{l}\text { Bv9g210020_yige.t1 } \\
(\mathrm{XP} 010689549.1) \star\end{array}$ & 274 & 29.64 & 8.97 & 6 & plas & plas \\
\hline & BvPIP 2;4 & reke & Bv9g-216070_reke.t1 & 281 & 30.13 & 8.84 & 6 & plas & plas \\
\hline \multirow{7}{*}{ TIP } & BvTIP $1 ; 1$ & kzkq & Bv7ug180930_kzkq.t1 & 254 & 26.06 & 5.38 & 6 & vacu & plas \\
\hline & BvTIP1;2 & iuuk & Bv2g037380_iuuk.t1 & 252 & 26.3 & 5.92 & 6 & vacu & vacu \\
\hline & BvTIP $1 ; 3$ & ynzf & Bv7g176430_ynzf.t1 & 248 & 25.46 & 5.13 & 6 & vacu & vacu \\
\hline & BvTIP2;1 & $\mathrm{dkzm}$ & Bv9g223310_dkzm.t1 & 247 & 25.26 & 5.6 & 6 & vacu & plas \\
\hline & BvTIP $2 ; 2$ & xunf & Bv5g104980_xunf.t1 & 249 & 25.09 & 4.7 & 7 & vacu & vacu \\
\hline & BvTIP3;1 & dreg & Bv8g190600_dreg.t1 & 257 & 27.13 & 7.07 & 5 & vacu & nucl/mito/vacu \\
\hline & BvTIP4;1 & ydno & Bv2g032200_ydno.t1 & 247 & 26.1 & 6.57 & 6 & vacu & cyto/vacu \\
\hline \multirow{10}{*}{ NIP } & BvTIP5;1 & gghp & Bv3ug068240_gghp.t1 & 255 & 26.54 & 8.47 & 6 & plas & chlo \\
\hline & BvNIP $1 ; 1$ & ughi & Bv8ug202570_ughi.t1 & 292 & 30.87 & 8.91 & 6 & plas & plas \\
\hline & BvNIP4;1 & aejh & Bv2g027680_aejh.t1 & 273 & 29.3 & 8.87 & 6 & plas & vacu \\
\hline & BvNIP4;2 & xash & Bv2g027660_xash.t1 & 299 & 32.62 & 8.27 & 6 & plas & plas \\
\hline & BvNIP 5;1 & gkiq & $\begin{array}{l}\text { Bv6TE021760_gkiq.t1 } \\
(\mathrm{XP} \text { _010680949.1) }\end{array}$ & 261 & 27.61 & 8.96 & 6 & plas & vacu \\
\hline & BvNIP 5;2 & oani & Bv6g139140_oani.t1 & 298 & 30.9 & 8.73 & 6 & plas & plas \\
\hline & BvNIP6;1 & hmzo & Bv9g225280_hmzo.t1 & 306 & 31.75 & 7.66 & 6 & plas & plas \\
\hline & BvNIP6;2 & zkgo & $\begin{array}{l}\text { Bv5g108450_zkgo.t1 } \\
(\mathrm{XP} \text { _010677474.1) }\end{array}$ & 266 & 27.46 & 7.82 & 6 & plas & plas \\
\hline & BvNIP6;3 & jecw & $\begin{array}{l}\text { Bv5g108440_jecw.t1 } \\
(\mathrm{XP} \text { _010677699.1) }\end{array}$ & 327 & 35.08 & 9.03 & 6 & plas & plas \\
\hline & BvNIP7;1 & kqew & Bv3ug070540_kqew.t1 & 289 & 30.72 & 7.13 & 7 & plas & plas \\
\hline \multirow{3}{*}{ SIP } & BvSIP $1 ; 1 \alpha$ & zywx & $\begin{array}{l}\text { Bv2g035790_zywx.t1 } \\
(\mathrm{XP} \text { 010669579.1) }\end{array}$ & & & 9.46 & 5 & plas & plas \\
\hline & BvSIP $1 ; 1 \beta$ & fzwq & Bv2g035780 fzwq.t1 & $\begin{array}{l}250 \\
247\end{array}$ & $\begin{array}{l}26.46 \\
26.39\end{array}$ & 9.74 & 6 & plas/vacu & vacu \\
\hline & BvSIP2;1 & qzqg & $\begin{array}{l}\text { Bv3g064810_qzqg.t1 } \\
(\mathrm{XP} \text { _010673209.1) }\end{array}$ & 236 & 26.02 & 9.56 & 5 & plas & vacu \\
\hline XIP & BvXIP1;1 & iwpe & Bv9g217040_iwpe.t1 & 312 & 34.13 & 8.38 & 7 & plas & plas \\
\hline
\end{tabular}

Note1: Best possible cell localization prediction by the Plant-mPLoc and WoLF PSORT tool (Chlo: membrane; Vacu: vacuolar membrane).

173 Note2: $\star$ sequences were splicing errors in AnnoBeet, and were corrected by NCBI Beta vulgaris (ID 221) - Genome. These were verified by PCR amplification. 


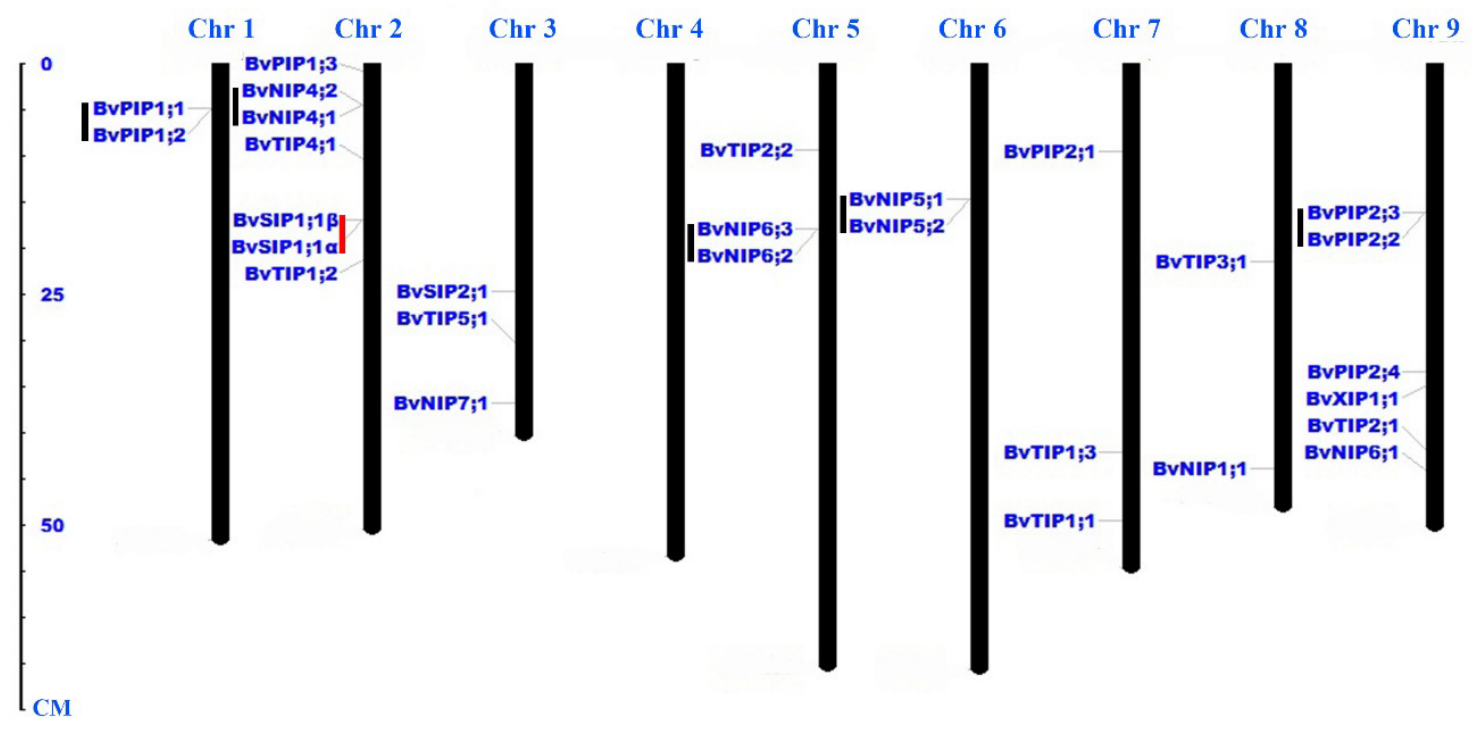

Fig 2 Distribution of $B v A Q P$ genes on the nine $B$. vulgaris chromosomes

Note: Black lines represent tandem gene duplications. Red lines represent the existence of different transcripts from single gene.

2. Genes mapping on the sugar beet chromosomes, gene duplications, gene structure and alternative splicing

$28 A Q P$ genes were unevenly mapped on 8 chromosomes (Fig 2). Seven $B v A Q P$ genes (25\%) mapped on chromosome (Chr) 2, 6 BvAQP genes (21\%) mapped on Chr9. Chr3, Chr5 and Chr7 each had $3 B v A Q P$ genes (10\%) and Chr1, Chr6 and Chr8 each had $2 B v A Q P$ genes. No putative AQP was found on Chr4. Tandem duplication events were found on Chr1, Chr2, Chr5, Chr6 and Chr8 (i.e. BvPIP1;1 and BvPIP1;2,BvNIP4;1 and BvNIP4;2, BvNIP6;2 and BvNIP6;3, 


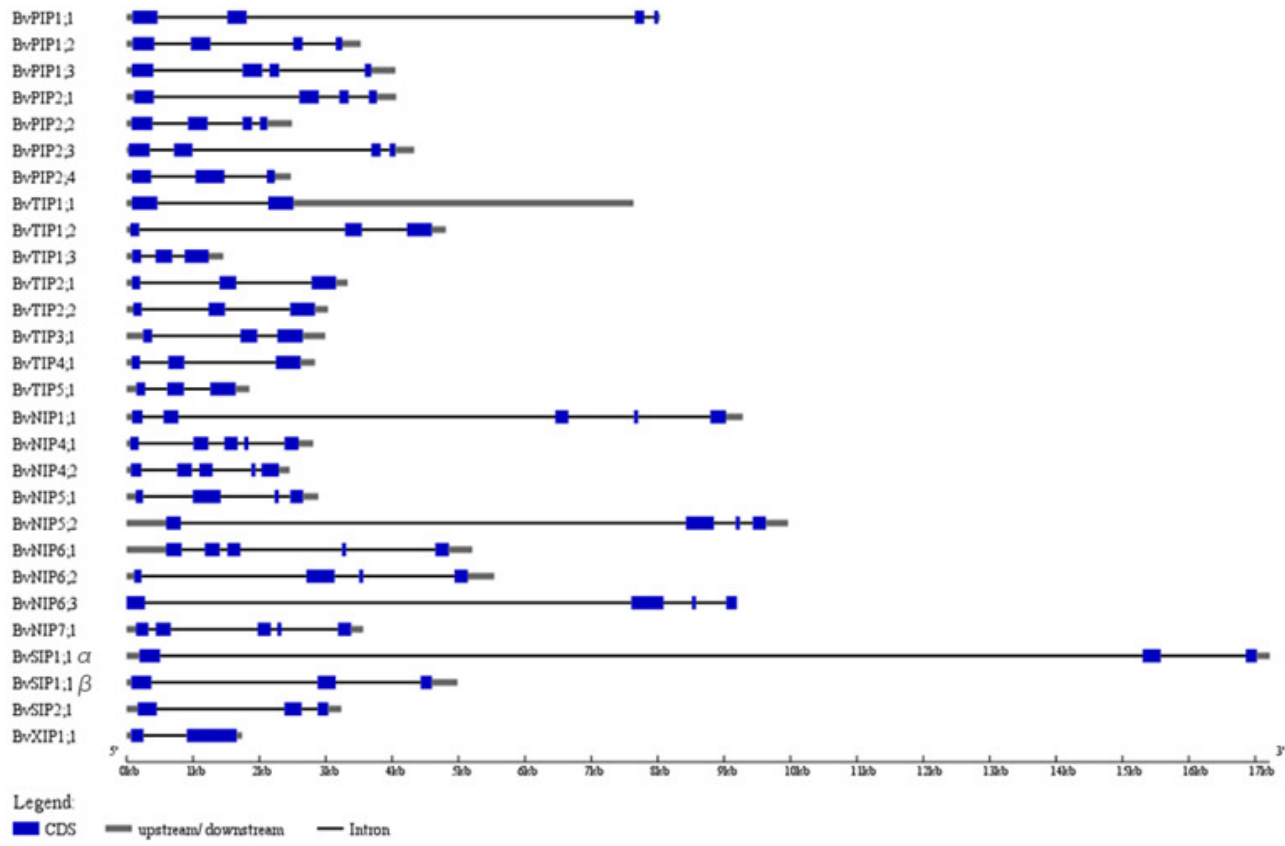

Fig $3 B v A Q P$ genes structure analysis

196

The exon-intron structures play crucial roles during plant evolution. The sugar beet AQPs exonintron structures are showed in Fig 3. Most PIP subfamily genes have 4 exons, while $B v P I P 1 ; 3$ had 5 and BvPIP2;4 had 3. TIP subfamily genes had 3 exons; specially, the third exon of BvTIP 1; 1 had a noncoding exon and codes a long 5' translated region (5' UTR). NIP subfamily genes had 5 exons with the exception BvNIP5;2, BvNIP6;2 and BvNIP6;3 had 4 exons. Most SIP subfamily genes have 3 exons but $B v X I P 1 ; 1$ only had 2 exons, which were similar to situations reported in common bean, tomato, potato, etc. (Ariani \& Gepts 2015; Reuscher et al. 2013a; Venkatesh et al. 2013). These results suggested that BvAQP gene structure is globally conserved in sugar beet. The conserved exon-intron structure provided an additional proof to support the classification results (Fig 1).

To seek further insights into the gene structure, the splicing pattern of sugar beet $B v A Q P$ premRNA sequence were analyzed. The splicing analysis revealed that $B v S I P 1 ; 1 \alpha$ is the result of second exon skipping (Fig 4). Amino acid sequence of $B v S I P 1 ; 1 \alpha$ and $B v S I P 1 ; 1 \beta$ shows $74.8 \%$ 210 similarity. 


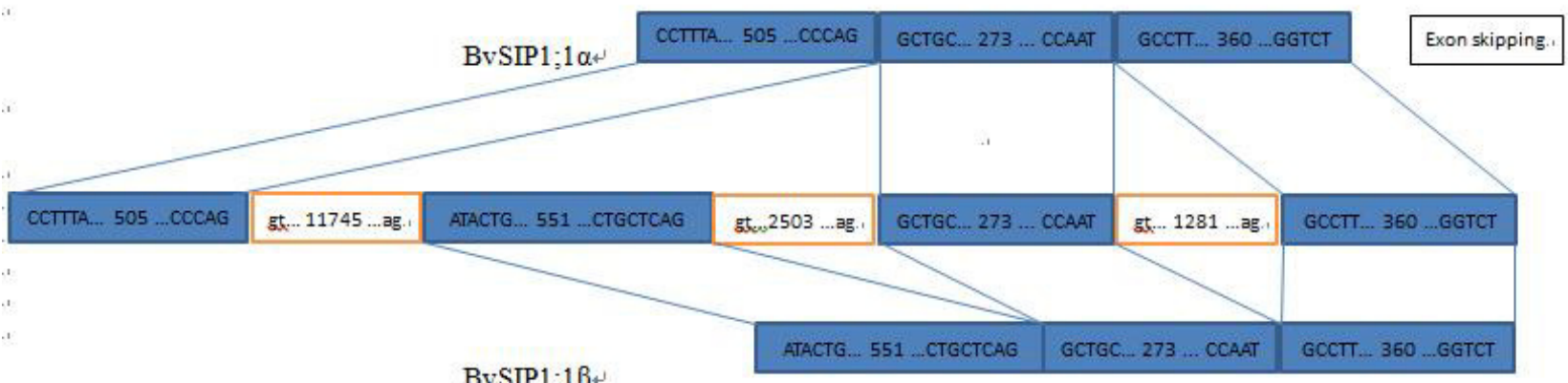

BvSIP $1 ; 1 \beta$

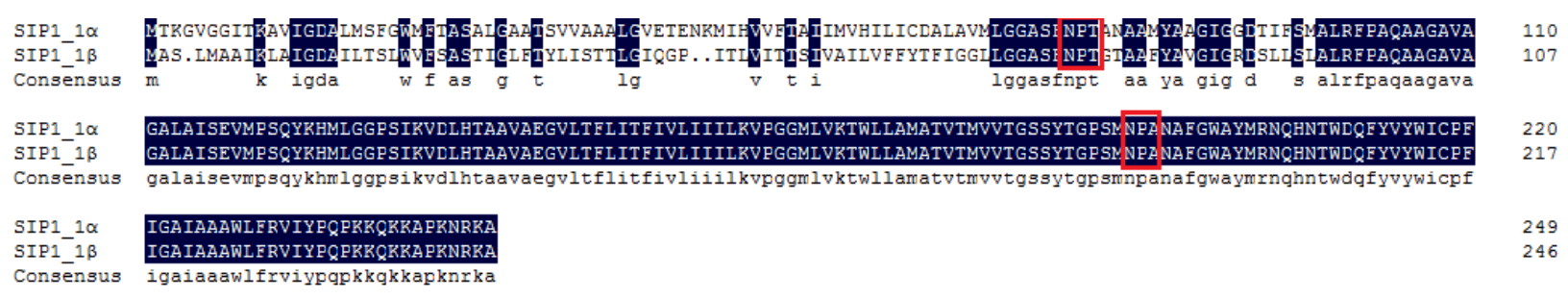

212

Fig 4 Alternative splicing of SIP1;1 generate two different transcripts: SIP1;1a and SIP1;1及

Table 2 Conserved dual NPA motifs, ar/R (H2, H5, LE1 and LE2), Froger's positions (P1-P5) analysis of 


\begin{tabular}{|c|c|c|c|c|c|c|c|c|c|c|c|c|}
\hline \multirow{2}{*}{ Subfamily } & \multirow[b]{2}{*}{ Gene } & \multicolumn{2}{|c|}{$\mathrm{NPA}$} & \multicolumn{4}{|c|}{$\mathrm{Ar} / \mathrm{R}$ selectivity filter } & \multicolumn{5}{|c|}{ Froger's position } \\
\hline & & LB & LE & $\mathrm{H} 2$ & $\mathrm{H} 5$ & LE1 & LE2 & P1 & P2 & P3 & P4 & P5 \\
\hline \multirow[t]{7}{*}{ PIP } & BvPIP $1 ; 1$ & NPA & NPA & $\mathrm{F}$ & $\mathrm{H}$ & $\mathrm{T}$ & $\mathrm{R}$ & $\mathrm{Q}$ & $S$ & A & $\bar{F}$ & $\mathrm{~W}$ \\
\hline & BvPIP $1 ; 2$ & NPA & NPA & $\mathrm{F}$ & $\mathrm{H}$ & $\mathrm{T}$ & $\mathrm{R}$ & $\mathrm{Q}$ & S & A & $*$ & $*$ \\
\hline & BvPIP $1 ; 3$ & NPA & NPA & F & $\mathrm{H}$ & $\mathrm{T}$ & $\mathrm{R}$ & $\mathrm{Q}$ & S & A & F & $\mathrm{W}$ \\
\hline & BvPIP2;1 & NPA & NPA & $\mathrm{F}$ & $\mathrm{H}$ & $\mathrm{T}$ & $\mathrm{R}$ & $\mathrm{Q}$ & S & A & $\mathrm{F}$ & W \\
\hline & BvPIP2;2 & NPA & NPA & $\mathrm{F}$ & $\mathrm{H}$ & $\mathrm{T}$ & $\mathrm{R}$ & $\mathrm{Q}$ & S & A & $\mathrm{F}$ & $\mathrm{W}$ \\
\hline & BvPIP2;3 & NPA & NPA & F & $\mathrm{H}$ & $\mathrm{T}$ & $\mathrm{R}$ & $\mathrm{Q}$ & S & A & F & $\mathrm{W}$ \\
\hline & BvPIP2;4 & NPA & NPA & $\mathrm{F}$ & $\mathrm{H}$ & $\mathrm{T}$ & $\mathrm{R}$ & M & S & A & $\mathrm{F}$ & W \\
\hline \multirow[t]{8}{*}{ TIP } & BvTIP $1 ; 1$ & NPA & NPA & $\mathrm{H}$ & I & A & $\mathrm{V}$ & $\mathrm{T}$ & S & A & $\mathrm{Y}$ & W \\
\hline & BvTIP $1 ; 2$ & NPA & NPA & $\mathrm{H}$ & I & A & $\mathrm{V}$ & $\mathrm{T}$ & S & A & $\mathrm{Y}$ & W \\
\hline & BvTIP $1 ; 3$ & NPA & NPA & $\mathrm{H}$ & I & A & $\mathrm{V}$ & $\mathrm{T}$ & S & A & $\mathrm{Y}$ & W \\
\hline & BvTIP2;1 & NPA & NPA & $\mathrm{H}$ & I & G & $\mathrm{R}$ & $\mathrm{T}$ & S & A & $\mathrm{Y}$ & W \\
\hline & BvTIP2;2 & NPA & NPA & $\mathrm{H}$ & I & $\mathrm{G}$ & $\mathrm{R}$ & $\mathrm{T}$ & S & A & $\mathrm{Y}$ & W \\
\hline & BvTIP3;1 & NPA & NPA & $\mathrm{H}$ & I & A & $\mathrm{R}$ & $\mathrm{T}$ & A & A & $\mathrm{Y}$ & W \\
\hline & BvTIP4;1 & NPA & NPA & $\mathrm{H}$ & I & A & $\mathrm{R}$ & $\mathrm{T}$ & S & A & $\mathrm{Y}$ & W \\
\hline & BvTIP5;1 & NPA & NPA & $\mathrm{N}$ & $\mathrm{V}$ & $\mathrm{G}$ & $\mathrm{Y}$ & $\mathrm{T}$ & S & A & $\mathrm{Y}$ & W \\
\hline \multirow[t]{9}{*}{ NIP } & BvNIP 1;1 & NPA & NPA & $\mathrm{W}$ & $\mathrm{V}$ & $\mathrm{A}$ & $\mathrm{R}$ & $\mathrm{F}$ & S & A & $\mathrm{Y}$ & $\mathrm{L}$ \\
\hline & BvNIP4;1 & NPA & NPA & $\mathrm{W}$ & $\mathrm{V}$ & A & $\mathrm{R}$ & $\mathrm{F}$ & S & A & $\mathrm{Y}$ & I \\
\hline & BvNIP4;2 & NPS & NPA & $\mathrm{W}$ & A & $\mathrm{A}$ & $\mathrm{R}$ & $\mathrm{L}$ & S & A & $\mathrm{Y}$ & I \\
\hline & BvNIP 5;1 & NPS & NPV & A & I & $\mathrm{G}$ & $\mathrm{R}$ & $\mathrm{F}$ & $\mathrm{T}$ & A & $\mathrm{Y}$ & M \\
\hline & BvNIP 5;2 & NPS & NPV & A & I & A & $\mathrm{R}$ & $\mathrm{F}$ & $\mathrm{T}$ & A & $\mathrm{Y}$ & M \\
\hline & BvNIP6;1 & NPS & NPV & $\mathrm{S}$ & I & $\mathrm{G}$ & $\mathrm{R}$ & $\mathrm{F}$ & $\mathrm{T}$ & A & $\mathrm{Y}$ & $\mathrm{F}$ \\
\hline & BvNIP6;2 & NPA & NPA & S & I & G & $\mathrm{R}$ & $\mathrm{Y}$ & $\mathrm{T}$ & A & $\mathrm{Y}$ & M \\
\hline & BvNIP6;3 & NPA & NPA & $\mathrm{S}$ & I & A & $\mathrm{R}$ & $\mathrm{Y}$ & $\mathrm{T}$ & A & $\mathrm{Y}$ & $\mathrm{L}$ \\
\hline & BvNIP7;1 & NPA & NPA & A & $\mathrm{V}$ & G & $\mathrm{R}$ & $\mathrm{F}$ & S & A & $\mathrm{Y}$ & $\mathrm{F}$ \\
\hline \multirow[t]{3}{*}{ SIP } & BvSIP $1 ; 1 \alpha$ & NPT & NPA & I & $\mathrm{V}$ & $\mathrm{P}$ & $\mathrm{N}$ & M & A & A & $\mathrm{Y}$ & W \\
\hline & BvSIP $1 ; 1 \beta$ & NPT & NPA & V & $\mathrm{V}$ & $\mathrm{P}$ & $\mathrm{N}$ & M & A & A & $\mathrm{Y}$ & W \\
\hline & BvSIP2;1 & NPL & NPA & $\mathrm{S}$ & $\mathrm{N}$ & $\mathrm{G}$ & $\mathrm{S}$ & $\mathrm{F}$ & V & A & $\mathrm{Y}$ & W \\
\hline XIP & BvXIP $1 ; 1$ & NPT & NPA & $\mathrm{V}$ & $\mathrm{S}$ & $\mathrm{A}$ & $\mathrm{R}$ & $\mathrm{F}$ & $\mathrm{C}$ & $\mathrm{A}$ & $\mathrm{F}$ & W \\
\hline
\end{tabular}

A

口otif1

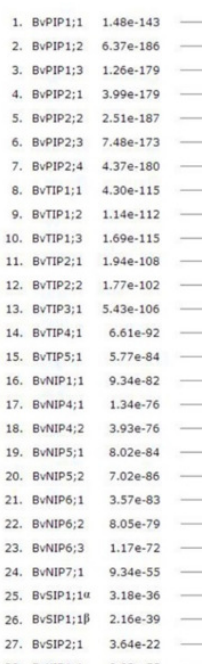

28. Bvxp1 $1 ; 1 \quad 9.63 \mathrm{e}-55$
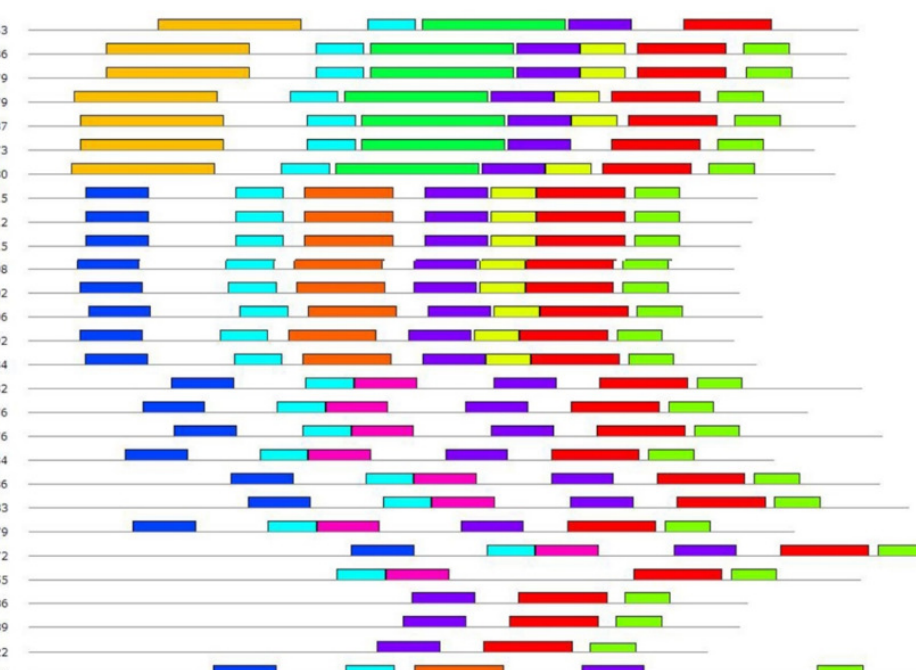

$\square \longrightarrow$
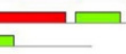

$+\frac{10}{2}$

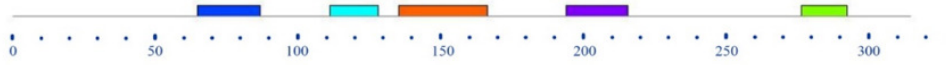

$\mathrm{B}$

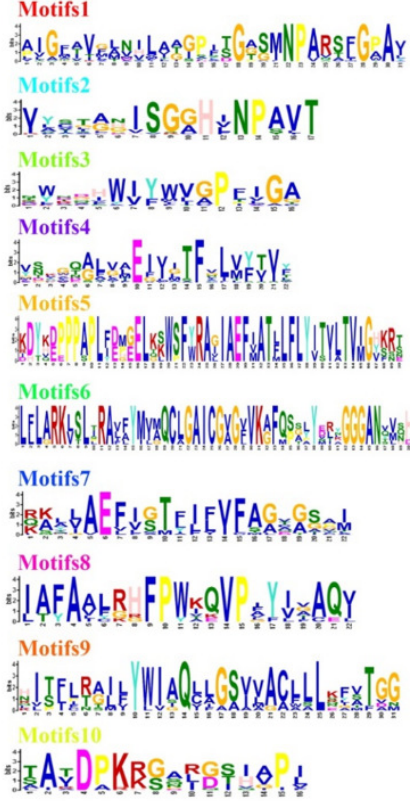

Motifs

B.

Motifs:

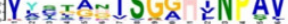

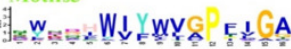

Motifs 4

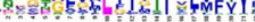

Motifs

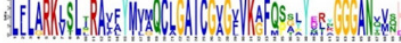

Motifs7

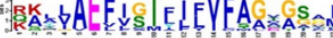

Motifs 8

AAFAAR F N W

Motifs9

:ATA $A$ A

Fig 5 BvAQPs protein motifs identified by MEME

Using the complete amino acid sequences of BvAQPs. Combined p-values are indicated in A, and different motifs were shown by different colors and numbered from 1 to 10 in B. 


\section{3. Conserved resides and conserved motifs distribution}

232 To further understand possible physiological role and substrate specificity of BvAQPs, they were

233

234

235

236

237

238

239

240

241

242

243

244

245

246

247

248

249

250

251

252

253

254

255

256

257

aligned and TMHs and conserved resides (NPA motifs, ar/R selectivity filter and Froger's position) were analyzed (Table 2). The data revealed that all BvAQPs had six characteristic TMHs for AQPs, required for transport function (Fig S1). However, BvPIP1;1 showed partial loss of TM6. The resulting missing protein domains may cause dominant negative effect on protein functions, although this need to be confirmed. All PIPs and TIPs showed the dual typical NPA motifs, but some members of NIPs such as BvNIP5;1, BvNIP5;2 and BvNIP6;1 showed that the Alanine (A) in the third residue of the second NPA motif was replace $d$ by a Valine (V). All SIPs and NIPs showed various third residues in the first NPA motif, in which Alanine (A) was replaced by Threonine (T) or by a Leucine (L). PIPs' ar/R selectivity filter and Froger's position showed an apparent family-specificity compared to NPA motifs, with ar/R filter configuration typical for water-transporting AQPs (F-H-T-R) and Q/M-S-A-F-W residues in Froger's position. TIPs contained the $\mathrm{H}-\mathrm{I}-\mathrm{A} / \mathrm{G}-\mathrm{V} / \mathrm{R}$ residues in the ar/R selectivity filter and TS/A-A-Y-W residues in Froger's position, but BvTIP5;1 showed that the N-V-G-Y in the ar/R selectivity filter was different from other TIPs and formed a single-gene clade with the TIPs. In NIPs, the ar/R selectivity filter and Froger's position had multiple types. BvNIP1;1, BvNIP4;1 and BvNIP4;2 showed W-V-A-R in the ar/R selectivity filter and F/L-S-A-Y-L/I in the Froger's position. BvNIP5;1 and BvNIP5;2 showed A-I-G/A-R in the ar/R selectivity filter and F-T-A-Y$\mathrm{M}$ in the Froger's position. BvNIP6;1, BvNIP6;2 and BvNIP6;3 showed S-I-G/A-R in the ar/R selectivity filter and Y-T-A-Y-F/M/L in the Froger's position. BvNIP7;1 showed A-V-G-R in the ar/R selectivity filter and F-S-A-Y-F in the Froger's position. SIP1s and SIP2s showed distinct difference in the ar/R selectivity filter and the Froger's position. BvSIP1;1 $\alpha$ and BvSIP1;1 $\beta$ showed I/V-V-P-N ar/R selectivity filter and M-A-A-Y-W in the Froger's position, but BvSIP2;1 showed S-N-G-S ar/R selectivity filter and F-V-A-Y-W in the Froger's position. BvXIP1;1 showed V-S-A-R ar/R selectivity filter and F-C-A-F-W in the Froger's position. To explore further the diversity in each group, the conserved motifs were predicted (Fig 5). Motifs 5 
258

259

260

261

262

263

264

265

266

267

268

269

270

271

272

273

274

275

276

277

278

279

280

281

282

283

284

and 6 appeared specifically in PIPs; Motif 8, in NIPs; Motif 9 in TIPs and XIPs.

\section{Subcellular localization}

Plant-mPLoc prediction was used to predict BvAQPs subcellular localization (Table 1). PIPs, NIPs, TIPs and SIPs (except BvSIP1;1 $\beta$ ) were predicted to localize to plasma membrane and all TIPs were also predicted to localize on vacuolar membrane. However, subcellular localizations predicted by WoLF PSORT were diverse and not always in agreement with that predicted by Plant-mPLoc (Table 1). For example, most PIPs were predicted to localize on plasma membrane. TIPs were predicted to localize on vacuolar membrane, plasma membrane as well as in the nucleus, mitochondria, cytosol and chloroplast. NIPs, SIPs and XIPs were predicted to localize on vacuolar membrane and plasma membrane. Although these predications represent a starting base, more experiments, i.e. with tagged proteins, are will be useful better characterize the subcellular localization of BvAQPs.

\section{Expression analysis of sugar beet AQP genes in different organs and in response to salt}

\section{\& heat stress}

We used the available RNA-seq data from different organs and young leaf under heat, salt stress treatment of B. vualgaris (Dohm et al. 2014; Minoche et al. 2015) to evalute tha expression of BvAQPs. 27 BvAQP genes (96\%) were expressed in at least one tissue (Fig 6, Table S1) and one $B v A Q P$ gene $(N I P 6 ; 3)$ did not show any expression in all tested plant organs. $18 B v A Q P$ genes (64\%) expressed in all organs, including 6 PIP, 4 TIP, 4 NIP, 3 SIP and 1 XIP. 26 BvAQP genes (92\%) expressed in taproot, with BvPIP1;3, BvTIP1;1 and BvPIP2;4 exhibiting the highest expression levels. $26 A Q P$ genes (92\%) were expressed in inflorescence, among which BvPIP2;4, $B v P I P 1 ; 3$ and BvTIP1;1 exhibiting the highest expression levels. $22 A Q P$ genes (79\%) were expressed in seed (with BvTIP3;1, BvPIP2;1, BvPIP1;3 and BvTIP1;1 showing the highest expression levels). only $18 A Q P$ genes (64\%) were expressed in leaf (BvTIP1;1, BvPIP1;3 and BvTIP2; 1 showed the highest expression levels). Most genes were expressed constitutively in the 
285 tested tissues, while one gene $(B v T I P 5 ; 1)$ showed tissue-specific expression in the inflorescence.

286 In addition, the transcripts of $B v T I P 1 ; 2$ and $B v N I P 7 ; 1$ were also shown to be relatively abundant

287 in inflorescence and BvTIP2;2 was highly expressed in taproot and seeding.

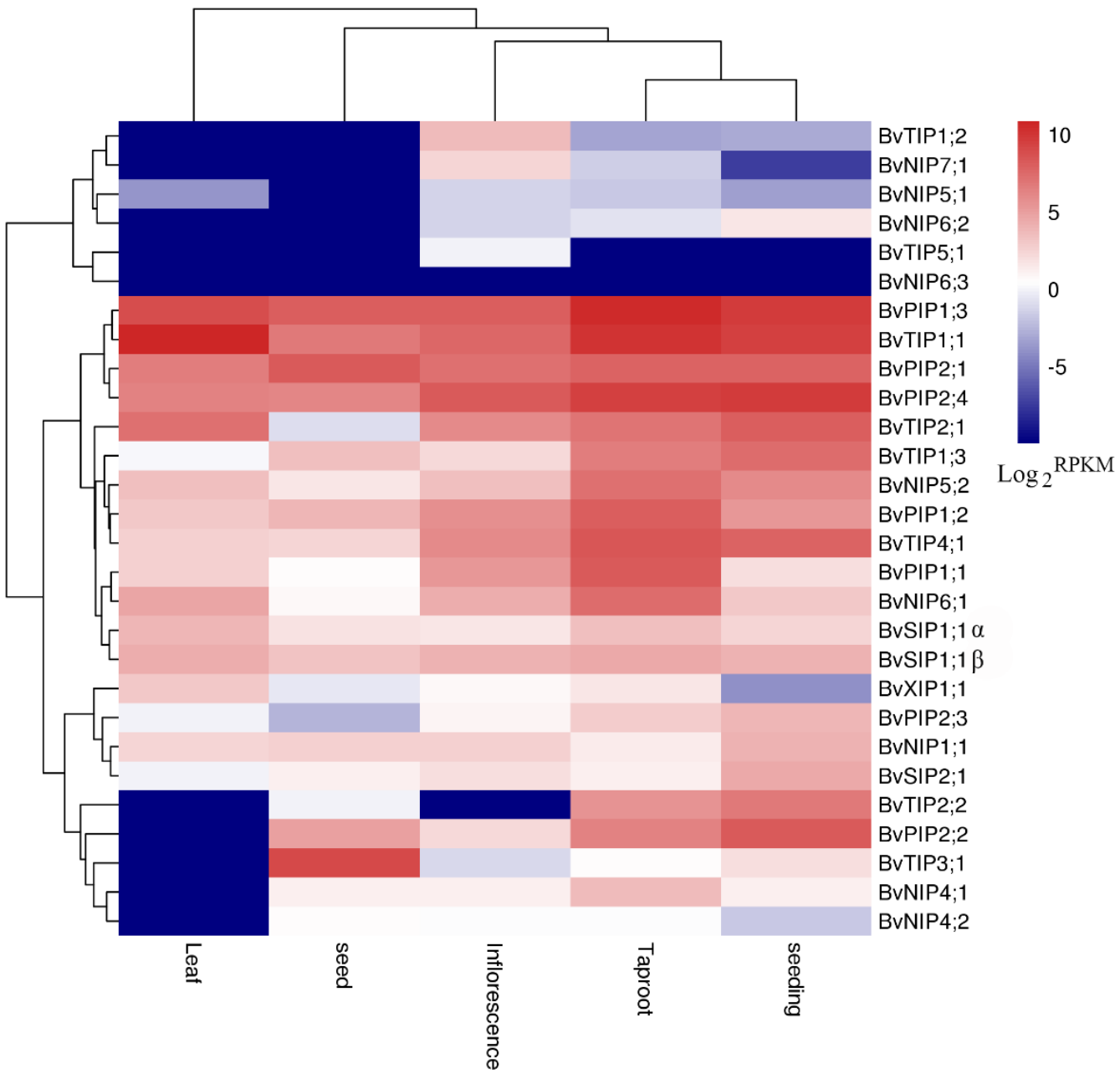

Fig 6 Expression profiles of the $28 B v A Q P$ genes in different plant organs and tissues 


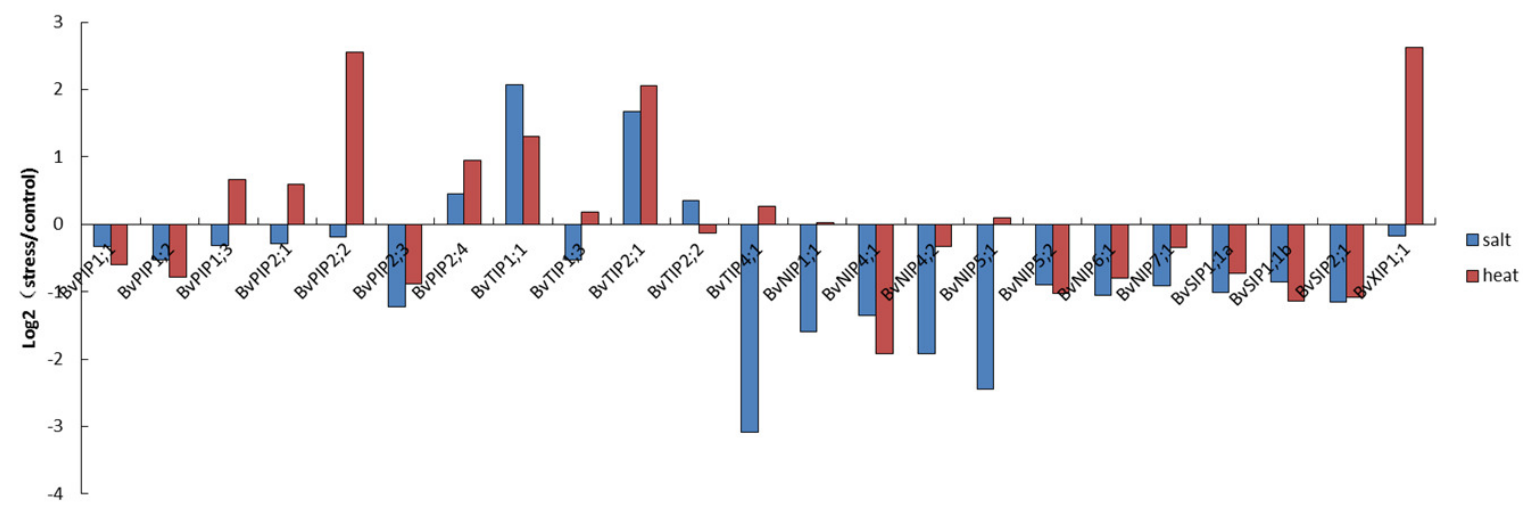

Fig 7 Expression pattern of the $23 B v A Q P$ genes in young leaf under abiotic stress.

294

295

296

Table 3 Identified typical SDPs in BvAQPs 


\begin{tabular}{|c|c|c|c|c|c|c|c|c|c|c|}
\hline \multirow{2}{*}{\multicolumn{2}{|c|}{ Aquaporin }} & \multicolumn{9}{|c|}{ Specificity-determining positions } \\
\hline & & SDP1 & SDP2 & SDP3 & SDP4 & SDP5 & SDP6 & SDP7 & SDP8 & SDP9 \\
\hline \multirow[t]{2}{*}{ Typical } & $\mathrm{NH}_{3}$ transporter & $\mathrm{F} / \mathrm{T}$ & $\mathrm{K} / \mathrm{L} / \mathrm{N} / \mathrm{V}$ & $\mathrm{F} / \mathrm{T}$ & $\mathrm{V} / \mathrm{L} / \mathrm{T}$ & A & $\mathrm{D} / \mathrm{S}$ & $\mathrm{A} / \mathrm{H} / \mathrm{L}$ & $\mathrm{E} / \mathrm{P} / \mathrm{S}$ & $\mathrm{A} / \mathrm{R} / \mathrm{T}$ \\
\hline & BvNIP $1 ; 1$ & $\mathrm{~F}$ & $\mathrm{H}$ & $\mathrm{F}$ & $\mathrm{T}$ & A & D & $\mathrm{L}$ & $\mathrm{E}$ & $\mathrm{T}$ \\
\hline \multirow[t]{6}{*}{ Typical } & Boric Acid transporter & $\mathrm{T} / \mathrm{V}$ & $\mathrm{I} / \mathrm{V}$ & $\mathrm{H} / \mathrm{I}$ & $\mathbf{P}$ & $\mathbf{E}$ & $\mathrm{I} / \mathrm{L}$ & $\mathrm{I} / \mathrm{L} / \mathrm{T}$ & $\mathrm{A} / \mathrm{T}$ & $\mathrm{A} / \mathrm{G} / \mathrm{K} / \mathrm{P}$ \\
\hline & BvPIP $1 ; 2$ & $\mathrm{~T}$ & I & $\mathrm{H}$ & $\mathrm{P}$ & $\mathrm{E}$ & $\mathrm{L}$ & $\mathrm{L}$ & $\mathrm{T}$ & $\mathrm{P}$ \\
\hline & BvPIP $1 ; 3$ & $\mathrm{~T}$ & I & $\mathrm{H}$ & $\mathrm{P}$ & $\mathrm{E}$ & $\mathrm{L}$ & $\mathrm{L}$ & $\mathrm{T}$ & $\mathrm{P}$ \\
\hline & BvNIP5;2 & $\mathrm{T}$ & I & $\mathrm{H}$ & $\mathrm{P}$ & $\mathrm{E}$ & $\mathrm{L}$ & $\mathrm{L}$ & A & $\mathrm{P}$ \\
\hline & BvNIP $6 ; 1$ & $\mathrm{~T}$ & I & $\mathrm{H}$ & $\mathrm{P}$ & $\mathrm{E}$ & $\mathrm{L}$ & $\mathrm{L}$ & A & $\mathrm{P}$ \\
\hline & BvXIP1; 1 & $\mathrm{~T}$ & I & $\mathrm{H}$ & $\mathrm{P}$ & $\mathrm{E}$ & $\mathrm{L}$ & $\mathrm{L}$ & $\mathrm{T}$ & $\mathrm{P}$ \\
\hline \multirow[t]{4}{*}{ Typical } & C02 transporter & $\mathrm{I} / \mathrm{L} / \mathrm{V}$ & I & C & $\mathbf{A}$ & $\mathrm{I} / \mathrm{V}$ & D & $W$ & D & W \\
\hline & BvPIP $1 ; 2$ & V & M & $\mathrm{C}$ & $\mathrm{A}$ & I & D & W & $\mathrm{H}$ & W \\
\hline & BvPIP1; 3 & V & M & $\mathrm{C}$ & A & I & $\mathrm{H}$ & W & D & W \\
\hline & BvPIP2; 1 & $\mathrm{I}$ & M & $\mathrm{C}$ & A & V & K & W & D & W \\
\hline \multirow[t]{8}{*}{ Typical } & H202 Transporters & $\mathrm{A} / \mathrm{S}$ & $A / G$ & $\mathrm{~L} / \mathrm{V}$ & $\mathrm{A} / \mathrm{F} / \mathrm{L} / \mathrm{T} / \mathrm{V}$ & $\mathrm{I} / \mathrm{L} / \mathrm{V}$ & $\mathrm{H} / \mathrm{I} / \mathrm{L} / \mathrm{Q}$ & $F / Y$ & $\mathrm{~A} / \mathrm{V}$ & $\mathbf{P}$ \\
\hline & BvPIP2 $; 1$ & $\mathrm{~A}$ & G & V & $\mathrm{F}$ & I & $\mathrm{H}$ & $\mathrm{F}$ & V & $\mathrm{P}$ \\
\hline & BvPIP2;2 & $\mathrm{A}$ & G & V & $\mathrm{F}$ & I & $\mathrm{H}$ & $\mathrm{F}$ & V & $\mathrm{P}$ \\
\hline & BvPIP $2 ; 3$ & A & G & V & $\mathrm{F}$ & I & $\mathrm{H}$ & $\mathrm{F}$ & V & $\mathrm{P}$ \\
\hline & BvPIP $2 ; 4$ & $\mathrm{~A}$ & G & V & $\mathrm{F}$ & I & $\mathrm{H}$ & $\mathrm{F}$ & V & $\mathrm{P}$ \\
\hline & BvTIP1; 1 & $\mathrm{~S}$ & A & $\mathrm{L}$ & A & I & $\mathrm{H}$ & Y & V & $\mathrm{P}$ \\
\hline & BvTIP $3 ; 1$ & A & A & $\mathrm{L}$ & $\mathrm{T}$ & I & $\mathrm{H}$ & Y & V & $\mathrm{P}$ \\
\hline & BvNIP4;2 & $\mathrm{S}$ & A & $\mathrm{L}$ & $\mathrm{L}$ & I & $\mathrm{L}$ & $\mathrm{Y}$ & $\mathrm{V}$ & $P$ \\
\hline Typical & $\begin{array}{c}\text { Silicic Acid Transporters } \\
\text { Not found }\end{array}$ & $\mathrm{C} / \mathrm{s}$ & $\mathrm{F} / \mathrm{Y}$ & $\mathrm{A} / \mathrm{E} / \mathrm{L}$ & $\mathrm{H} / \mathrm{R} / \mathrm{Y}$ & G & $\mathrm{K} / \mathrm{N} / \mathrm{T}$ & $\mathbf{R}$ & $\mathrm{E} / \mathrm{S} / \mathrm{T}$ & $\mathrm{A} / \mathrm{K} / \mathrm{P} / \mathrm{T}$ \\
\hline \multirow[t]{23}{*}{ Typical } & Urea Transporters & $\mathrm{H}$ & $\mathbf{P}$ & $\mathrm{F} / \mathrm{I} / \mathrm{L} / \mathrm{T}$ & $\mathrm{A} / \mathrm{C} / \mathrm{F} / \mathrm{L}$ & $\mathrm{L} / \mathrm{M}$ & $\mathrm{A} / \mathrm{G} / \mathrm{P}$ & $\mathrm{G} / \mathrm{S}$ & $\mathrm{G} / \mathrm{S}$ & $\mathrm{N}$ \\
\hline & BvPIP $1 ; 1$ & $\mathrm{H}$ & $\mathrm{P}$ & $\mathrm{F}$ & L & $\mathrm{L}$ & $\mathrm{P}$ & G & G & $\mathrm{N}$ \\
\hline & BvPIP1;2 & $\mathrm{H}$ & $\mathrm{P}$ & $\mathrm{F}$ & $\mathrm{L}$ & $\mathrm{L}$ & $\mathrm{P}$ & G & G & $\mathrm{N}$ \\
\hline & BvPIP $1 ; 3$ & $\mathrm{H}$ & $\mathrm{P}$ & $\mathrm{L}$ & $\mathrm{F}$ & $\mathrm{L}$ & $\mathrm{P}$ & G & G & $\mathrm{N}$ \\
\hline & BvPIP2 $; 1$ & $\mathrm{H}$ & $\mathrm{P}$ & $\mathrm{F}$ & $\mathrm{L}$ & $\mathrm{L}$ & $\mathrm{P}$ & G & G & $\mathrm{N}$ \\
\hline & BvPIP2 $; 2$ & $\mathrm{H}$ & $\mathrm{P}$ & $\mathrm{F}$ & $\mathrm{F}$ & $\mathrm{L}$ & $\mathrm{P}$ & G & G & $\mathrm{N}$ \\
\hline & BvPIP $2 ; 3$ & $\mathrm{H}$ & $\mathrm{P}$ & $\mathrm{F}$ & $\mathrm{F}$ & $\mathrm{L}$ & $\mathrm{P}$ & G & G & $\mathrm{N}$ \\
\hline & BvPIP $2 ; 4$ & $\mathrm{H}$ & $\mathrm{P}$ & $\mathrm{F}$ & $\mathrm{F}$ & $\mathrm{L}$ & $\mathrm{P}$ & G & G & $\mathrm{N}$ \\
\hline & BvTIP1; 1 & $\mathrm{H}$ & $\mathrm{P}$ & $\mathrm{F}$ & $\mathrm{F}$ & $\mathrm{L}$ & A & G & S & $\mathrm{N}$ \\
\hline & BvTIP $1 ; 2$ & $\mathrm{H}$ & $\mathrm{P}$ & $\mathrm{F}$ & $\mathrm{F}$ & $\mathrm{L}$ & $\mathrm{P}$ & G & S & $\mathrm{N}$ \\
\hline & BvTIP1; 3 & $\mathrm{H}$ & $\mathrm{P}$ & L & $\mathrm{F}$ & $\mathrm{L}$ & A & G & S & $\mathrm{N}$ \\
\hline & BvTIP $2 ; 1$ & $\mathrm{H}$ & $\mathrm{P}$ & $\mathrm{F}$ & A & $\mathrm{L}$ & $\mathrm{P}$ & G & S & $\mathrm{N}$ \\
\hline & BvTIP $2 ; 2$ & $\mathrm{H}$ & $\mathrm{P}$ & $\mathrm{F}$ & A & $\mathrm{L}$ & $\mathrm{P}$ & G & S & $\mathrm{N}$ \\
\hline & BvTIP $3 ; 1$ & $\mathrm{H}$ & $\mathrm{P}$ & $\mathrm{F}$ & $\mathrm{L}$ & $\mathrm{L}$ & $\mathrm{P}$ & G & S & $\mathrm{N}$ \\
\hline & BvTIP4 $; 1$ & $\mathrm{H}$ & $\mathrm{P}$ & $\mathrm{L}$ & A & $\mathrm{L}$ & $\mathrm{L}$ & G & S & $\mathrm{N}$ \\
\hline & BvNIP1; 1 & $\mathrm{H}$ & $\mathrm{P}$ & I & A & $\mathrm{L}$ & $\mathrm{P}$ & G & S & $\mathrm{N}$ \\
\hline & BvNIP4 $; 1$ & $\mathrm{H}$ & $\mathrm{P}$ & $\mathrm{L}$ & A & $\mathrm{L}$ & $\mathrm{P}$ & G & S & $\mathrm{N}$ \\
\hline & BvNIP4; 2 & $\mathrm{H}$ & $\mathrm{P}$ & I & A & $\mathrm{L}$ & $\mathrm{T}$ & G & $\mathrm{S}$ & $\mathrm{N}$ \\
\hline & BvNIP5; 1 & $\mathrm{H}$ & $\mathrm{P}$ & I & A & $\mathrm{L}$ & $\mathrm{P}$ & G & S & $\mathrm{N}$ \\
\hline & BvNIP5; 2 & $\mathrm{H}$ & $\mathrm{P}$ & I & A & $\mathrm{L}$ & $\mathrm{P}$ & G & S & $\mathrm{N}$ \\
\hline & BvNIP $6 ; 1$ & $\mathrm{H}$ & $\mathrm{P}$ & I & A & $\mathrm{L}$ & $\mathrm{P}$ & G & S & $\mathrm{N}$ \\
\hline & BvNIP6 ; 2 & $\mathrm{H}$ & $\mathrm{P}$ & $\mathrm{L}$ & A & $\mathrm{L}$ & $\mathrm{P}$ & G & S & $\mathrm{N}$ \\
\hline & BvNIP $6 ; 3$ & $\mathrm{H}$ & $\mathrm{P}$ & I & $\mathrm{A}$ & $\mathrm{L}$ & $\mathrm{P}$ & $\mathrm{G}$ & $\mathrm{S}$ & $\mathrm{N}$ \\
\hline
\end{tabular}

298

299

300

301

302

303

304

305

306

307

308

The expression patterns of sugar beet AQP genes were found to fluctuate under different stress conditions. $11 A Q P$ genes (44\%) expression were down-regulated both under salt and heated stress. These include $B v P I P 1 ; 1, B v P I P 1 ; 2, B v P I P 2 ; 3, B v N I P 4 ; 1, B v N I P 4 ; 2, B v N I P 5 ; 2$, BvNIP6;1, BvNIP7;1, BvSIP1;1 $\alpha, B v S I P 1 ; 1 \beta$ and BvSIP2;1 (Fig 7). In contrast, the expression of BvPIP2;4, BvTIP1;1 and BvTIP2;1 (12\%) was up-regulated both under salt and heated stress. Interestingly, $9 A Q P$ genes showed different expression in response to salt or heat treatments. Eight among these $A Q P$ genes $(32 \% ; B v P I P 1 ; 3, B v P I P 2 ; 1, B v P I P 2 ; 2, B v T I P 3 ; 1, B v T I P 4 ; 1$, $B v N I P 1 ; 1, B v N I P 5 ; 1$ and $B v X I P 1 ; 1)$ were up-regulated under heat treatment but down-regulated 
309

310

311

312

313

314

315

316

317

318

319

320

321

322

323

324

325

326

327

328

329

330

331

332

333

334

335

under salt treatment. Notably, members of PIP genes and XIP genes (BvPIP1;3, BvPIP2;1, $B v P I P 2 ; 2, B v X I P 1 ; 1)$ were highly up-regulated under heat stress but slightly down-regulated under salt stress, while members of TIP genes and NIP genes showed the opposite behavior, especially $B v T I P 4 ; 1, B v N I P 1 ; 1$ and $B v N I P 5 ; 1$. Only BvTIP2;2 (4\%) were up-regulated under salt but down-regulated under heat stress.

Interestingly, BvNIP6;3 wasn't expressed in all organs, neither in young leaf under salt and heat stress (Fig 6; Table S1), and BvNIP6;3 formed a single-gene clade within the NIP6s, with the highest MV (35.08kDa) and longest protein length (Table 1), but lacking Motif 4 compared to other AQPs (Fig 5). In addition, gene duplication analysis revealed BvNIP6;3 and BvNIP6;2 were tandem duplication (Fig 2) and suggested that BvNIP6;3 was originated from BvNIP6;2 and was pseudo-genes.

Other genes, such as $B v T I P 1 ; 2, B v T I P 3 ; 1, B v N I P 6 ; 2$ and BvNIP6;3 were not expressed in nontreated or in stressed leafs. BvTIP5;1 was not expressed in control or stressed leafs, but showed only very expression in young leaf under salt stress (Table S1).

\section{Discussion}

Many studies have confirmed that $A Q P$ genes were involved in plant water transport, in regulating growth and development and that they are widely distributed in animals and plants. Most functional studies of $A Q P$ genes were mainly conducted using model plants, such as $A$. thaliana, N. tabacum L., Z. mays L. and O. sativa L. Almost no or very little is known about $B$. vulgaris AQPs. Here we report the first investigation of AQPs in sugar beet. $28 A Q P$ genes were identified, including 7 PIP, 8 TIP, 9 NIP, 3 SIP, 1 XIP.

The number of AQPs genes in B. vulgaris is similar to that of D. caryophyllus (Morita et al. 2017), a closely related species belonging to the same family. B. vulgaris contains less AQP genes compared to plants that did undergo 1-3 times of whole genome duplication (WGD), fragment duplication (FD) and/or tandem duplication (TD), such as G. max L (Zhang et al. 2013), Brassica rapa (Tao et al. 2014), Z. mays L. (Chaumont et al. 2001), O. sativa L (Nguyen et al. 
336

337

338

339

340

341

342

343

344

345

346

347

348

349

350

351

352

353

354

355

356

357

358

359

360

361

362

2013) and P. trichocarpa (Gupta \& R 2009). B. Vulgaris more AQP genes that basal plants such as P. patens, S. moellendorffii (Bowers et al. 2003; Doyle et al. 2008; Gupta \& R 2009; Yu \& Yang 2002; Zhang et al. 2013). Almost all subgroups of PIPs, TIPs, SIPs and XIPs are present in the Caryophyllaceae plants B. vulgaris and D. caryophyllus (Morita et al. 2017).

The relatively small number of $A Q P$ genes in sugar beet, compared to other higher plant species, is likely due to the fact that B. vulgaris did not undergo WGD. Moreover, the rapid expansion of NIP subfamily which led to the production of new subgroups, might have occurred after the divergence of the basal core dicot and core dicot. The divergence and proliferation of NIP subfamily may be an adaptive response to an ever-changing environment, playing crucial role in plants disease resistance and multi-stress (Liu \& Zhu 2010). Some studies also suggested that NIPs allow larger solutes, such as silicic acid, to permeate. O. sativa L genes OsNIP2;1 (Lsil), OsNIP2;2 (LsiO), and Hordeum vulgare L. HvNIP2;1 (HvLsil) transport silicon across the biomembrane and enhance the resistance of plants to biotic and abiotic stress (Chiba et al. 2009; Ma et al. 2006; Yamaji \& Ma 2009; Yamaji et al. 2008), and O. sativa L OsNIP2; 1 could also be permeable to water, urea, boric acid, arsenite (Ma et al. 2008; Mitani et al. 2008).

To analyze the evolutionary relationship and BvAQPs putative functions, an unrooted phylogenetic tree was constructed using aquaporins from $A$. thaliana (in which a complete set of AtAQP genes is well known, and D. caryophyllus (DcAQPs) (Johanson \& Kjellbom 2001; Morita et al. 2017). The c in the model plant A. thaliana and D. caryophyllus, closely related species to B. vulgaris. During the process of cluster analysis, two carnation AQPs (DcSIP2;1 and DcNIP5;1) aroused our attention and made us confused in classification at once. Previously, the classification of DcSIP2;1 and DcNIP5;1 was not well resolved (Morita et al. 2017). In the case of DcSIP2;1, it shared the highest similarity of $67 \%$ with BvSIP1;1 and 51\% with AtSIP1; 1 , and also shared the same NPA motifs, Ar/R selectivity filter and Froger's position with BvSIP1;1. It clustered closer to the SIP1 subgroup. In the case of DcNIP5;1, it farther clustered to NIP5 subgroup and clustered closer to NIP6 subgroup. The closest homolog of DcNIP5;1 is BvNIP6;3 (similarity is $51 \%$ ) and both proteins shares the same $\mathrm{Ar} / \mathrm{R}$ selectivity filter (S-I-A-R) with 
363

364

365

366

367

368

369

370

371

372

373

374

375

376

377

378

379

380

381

382

383

384

385

386

387

388

389

BvNIP6;3 and BvNIP6;1, with similar Ar/R selectivity filter (A-I-A-R) to DcNIP6;1. So DcNIP5;1 belongs to NIP6 subgroup.

Alternative splicing is a mechanism by which genes can produce multiple transcript variants protein products, which allows in turn to increase the diversity of gene functions. Alternative splicing plays an important role in various processes such as development, response to pathogen and to various abiotic stresses (Bove et al. 2008; Gassmann 2008; Jang et al. 2009; Reddy \& Golovkin 2010). A pair of splice variants (BvSIP1;1 $\alpha$ and BvSIP1;1 $\beta$ ) were found in BvAQPs. $B v S I P 1 ; 1 \alpha$ resulted from second exon skipping. First exon and second exon encoded the same 'NPT' type NPA motif, so $B v S I P 1 ; 1 \alpha$ and $B v S I P 1 ; 1 \beta$ shared similar amino acid sequence and protein topology. These two genes had similar expression pattern in different organs. It is possible that $B v S I P 1 ; 1 \alpha$ and $B v S I P 1 ; 1 \beta$ may have redundant function. Exon skipping splicing were also found in S. tuberosum, while St-SIP1;1 $\alpha$ and St-SIP1;1 $\beta$ also resulted from second exon skipping and shared similar expression pattern (Venkatesh et al. 2013). However, the identified alternative splicing event found for BvAQPs genes were not reported in other plant species, suggesting that selective splicing may be species-specific.

NPA motifs, ar/R selectivity filter and Froger's position were reported involved in substrate selection and transport activity. BvAQPs functions could be conferred based on the comparison of these residues with other plants AQPs. BvPIPs showed typical NPA motif, F-H-T-R highly conserved ar/R selectivity filter and Q-S-A-F-W Froger's position, this composition is highly conserved in PIPs of A. thaliana (Johanson \& Kjellbom 2001), Z. mays (Chaumont et al. 2001), S. lycopersicum (Reuscher et al. 2013b), P. trichocarpa (Gupta \& R 2009), G. max (Zhang et al. 2013) and B. rapa (Tao et al. 2014). This composition of PIPs was reported to likely regulate root and leaf hydraulics, facilitate the $\mathrm{CO}_{2}$ diffusion, affect photosynthesis (Gupta \& R 2009). Therefore, B. vulgaris homologous PIPs may have similar roles in regulating water absorption, plant hydraulics and $\mathrm{CO}_{2}$ diffusion. Based on the SDPs analysis proposed by Hove and Bhave (Hove \& Bhave 2011) (Table 3; Fig S2), all B. vulgaris PIPs represented urea-type SDPs, BvPIP1;1 and BvPIP1;2 represented boric acid-type SDPs, all PIP2s represented $\mathrm{H}_{2} \mathrm{O}_{2}$-type 
390

391

392

393

394

395

396

397

398

399

400

401

402

403

404

405

406

407

408

409

410

411

412

413

414

415

416

SDPs, thus supporting conserved functions. In addition, BvPIP1;2, BvPIP1;3 and BvPIP2;1 seemed to represent novel $\mathrm{CO}_{2}$-type SDPs (I/L/V-M-C-A-I/V-D/H/K-W-D-W) with the substitution of Ile for Met in SDP2 and the substitution of Asp to His/Lys in SDP6. Although the ar/R selectivity filter varied highly, plant TIPs were shown to transport water as efficiently as PIPs (Zhi et al. 2015). Additionally, BvTIP1;1, BvTIP1;2, BvTIP1;3, BvTIP3;1 and BvTIP4;1 contained dual conserved NPA motifs, H-I-A-V/R ar/R selectivity filter and T-S-A-Y-W Froger's position, which had the same composition of Citrus sinensis AQPs, such as CsTIP1s, CsTIP3s showed to transport urea and $\mathrm{H}_{2} \mathrm{O}_{2}$ (Hove \& Bhave 2011). Compared to other TIPs, BvTIP2;1 and BvTIP2;2 had H-I-G-R ar/R selectivity filter, and this type ar/R selectivity filter was experimentally proven to transport formamide (Hove \& Bhave 2011), suggesting BvTIPs play a crucial role in transporting a wide range molecules. All TIPs (exception of BvTIP5;1) represented urea-type SDPs, indicting transporting urea function. BvTIP1;1 and BvTIP3;1 represented $\mathrm{H}_{2} \mathrm{O}_{2}$-type SDPs, indicting transporting $\mathrm{H}_{2} \mathrm{O}_{2}$ potential capacity.

Substrate selection specificity of NIPs is largely determined by two pores formed by NPA motifs and ar/R selectivity filter respectively. 'W-V-A-R' type ar/R selectivity filter were proven to be permeable to uncharged molecules i.e. glycerol, formamide and water, implying that BvNIP1;1 and BvNIP4;1 may have similar functions. 'A/S/T-V/I-A/G-R' type ar/R selectivity filter were reported can transport glycerol, formamide and larger solutes, like urea, boric, but were impermeable to water. Besides, NPS/NPV aqueous pore and A-I-G-R ar/R selectivity filter was known as a boric acid transporter in A. thaliana AtNIP5;1, and orthologs BvNIP5;1 can be involved in boron transport in B. vulgaris, suggesting that NIPs could be involved in the transport of larger solutes. Based on SDPs analysis, all NIPs (except BvNIP7;1) are potential urea transporters, while BvNIP4;2 is a potential $\mathrm{H}_{2} \mathrm{O}_{2}$ transporters, BvNIP5;2 and BvNIP6;1 are potential boric acid transporters and finaly BvNIP1;1 could represent a novel $\mathrm{NH}_{3}$-type SDPs with $\mathrm{H}$ replaced $\mathrm{K} / \mathrm{L} / \mathrm{N} / \mathrm{V}$ at $\mathrm{SDP} 2$. It should be noticed that we were unable to find NIP2 subgroup and silicic acid-type SDP AQPs in sugar beet, suggesting that other types of SDPs AQPs could be involved in absorption of silicic during plant growth and development, in sugar 
417 beet. Sugar beet SIPs and XIPs exhibited great variety in ar/R selectivity filter and Froger's 418 position, with a variable first NPA motif compared to other AQPs subfamilies. It has been 419 reported that $A$. thaliana SIPs (AtSIP1;1 and AtSIP1;2) localize to endoplasmic reticulum (ER) 420 and facilitate water transport. SDPs analysis suggest that BvXIP1;1 can transport boric acid, it is 421 thus possible that BvXIP has different role in B. vulgaris.

422 Sequence alignment revealed that BvPIP1;1 codes for a truncated protein that lacks TM6 domain. 423 The absence of TM6 domain possibly affects subcellular localization, proper folding, and 424 oligomerization and transport activity of this truncated AQP in B. vulgaris. Similar truncated 425 AQP TdPIP2;1 has been reported to affect water transport activity in wheat (He et al., 2012; Hu 426 et al., 2012). RNA-seq analysis revealed that $A Q P$ genes were expressed in all examined tissues 427 of B. vulgaris, thus similar to previously reported data in maize (Chaumont et al. 2001), $A$. 428 Arabidopsis (Quigley 2001), tomato (Reuscher et al. 2013a) and potato (Venkatesh et al. 2013). 429 Total transcript abundance in the different examined tissues showed high expression levels in 430 organs involved in water absorption, transport and evaporation, such as taproot and leaf, 431 suggesting the main role of AQPs in water and nutrients transport. The RNA-seq data suggest 432 that BvAQPs may play a key role in radial and axial water transportation in sugar beet, thus in 433 agreement with Amodeo et al., (1999). Many AQPs show similar expression patterns, suggesting 434 that they may act synergistically in some tissues. Co-expression of tandem PIP2-PIP1 dimers in 435 Xenopus oocytes showed that they can form PIP2-PIP1 hetero-tetramers and synergistically 436 increase water transport capacity (Bellati et al. 2010; Jozefkowicz et al. 2013; Jozefkowicz et al. 437 2015). BvPIP1;3, BvTIP1;1 and BvPIP2;4 were considerably abundant in taproot and are likely 438 involved in water and nutrients transport in root. $B v P I P 2 ; 4, B v P I P 1 ; 3$ and $B v T I P 1 ; 1$ were 439 abundant in inflorescence and seeding, and could be involved in monitoring the water balance in 440 young tissues. According to their expression profiles, BvTIP1;1, BvPIP1;3 and BvTIP2;1 could 441 play key roles in leaf hydraulics. BvTIP3;1, BvPIP2;1, BvPIP1;3 and BvTIP1;1 were 442 considerably abundant in seed and therefore could be involved in water balance in seed. $443 \quad B v P I P 1 ; 3$ and $B v T I P 1 ; 1$ show high expression levels in all examined tissues, while $B v T I P 3 ; 1$ 
444 were only expressed in abundance in seed, and showed very low expression in other organs, 445 suggesting a key role in seed development. BvTIP3;1 closest homolog Arabidopsis AtTIP3;1 and 446 castor bean RcTIP3;1 also shared similar expression pattern. AtTIP3;1 was reported to be seed447 and embryo-specific $A Q P$ (Johnson et al. 1989). RcTIP3; 1 expressed preferentially in endosperm 448 of developing seeds and considerably low in germinating seed (Zou et al. 2015). Moreover, $449 B v P I P 2 ; 2$ and $B v T I P 2 ; 2$ were highly expressed in seeding where they may control the water 450 balance. In total, several $A Q P$ genes (like $B v T I P 3 ; 1, B v P I P 2 ; 1$, and $B v P I P 1 ; 3$ ) play a 451 constitutive role and some $A Q P$ genes (like $B v T I P 3 ; 1, B v P I P 2 ; 2$ and $B v T I P 2 ; 2$ ) play a specialized function in specific plants organs. In addition, it is noteworthy that several putative non-aqua transporter-encoding genes (i.e. BvNIP7;1, BvNIP4;1, BvXIP1;1, BvNIP5;2, BvNIP6;1 and $B v S I P 2 ; 1)$ were shown to be relatively high abundant in certain tissues. Compared to others tissues, transcript level of $B v N I P 4 ; 1, B v N I P 5 ; 2$ and $B v N I P 6 ; 1$ was considerably high in taproot. Similar to BvNIP7;1, Arabidopsis AtNIP7;1 (specifically expressed in anthers) encode for a less efficient boric acid transporter, compared to AtNIP5;1 and AtNIP6;1. It is possible that $B v N I P 7 ; 1$ plays a role in $\mathrm{B}$ absorption and balance in inflorescence tissue. $B v X I P 1 ; 1$ had relatively high expression level in leaf. Similarly, BvXIP1;1 the closest homolog to RcXIP1;1, also showed high expression levels in leaf, but their exact functions remain unclear and further functional investigation are required.

In this study, a large number of $B v A Q P$ genes showed transcriptional changes when exposed to salt and heat stresses. For example, BvTIP1;1 and BvTIP2;1 showed strong induction $\left(\log _{2^{-}}\right.$ based value $>1$ ) after salt stress; $B v P I P 2 ; 2, B v T I P 1 ; 1, B v T I P 2 ; 1$ and $B v X I P 1 ; 1$ showed strong induction (Log2-based value $>1$ ) after heat stress, suggesting an extensive response of $B v A Q P$ genes to abiotic stress and a potential function for improving sugar beet resistance to abiotic stress. The results were consistent with previously reported data that showed that BvPIP2;2 expression was up-regulated in response to high salt stress (Skorupakłaput et al. 2015). Biochemical and genetic evidence has demonstrated that some $A Q P$ genes (like TaAQP7, TaAQP8, TaNIP, MaPIP1;1, MusaPIP2;6 and NtAQP1) improve plants resistance to abiotic 
471 stress (Gao et al. 2010; Hu 2012; Sade 2010; Sreedharan et al. 2015; Xu et al. 2014; Zhou et al. 472 2012). Additionally, we noticed that $B v T I P 1 ; 1$ and $B v T I P 2 ; 1$ strongly induced by both salt and 473 heat stresses, suggesting that these two AQPs may play key roles in B. vulgaris adaption to 474 environmental changes, e.g. heat and salt stresses.

\section{Conclusions}

$47628 B v A Q P$ genes were identified based on genome data, chromosome distribution, phylogenetic,

477 protein characteristics, gene structural, gene duplication, conserved motifs and RNA-seq 478 expression analysis of $B v A Q P$ genes were further researched, Results suggested AQPs had 479 multiple functions in different tissues; several $B v A Q P$ genes responded to abiotic stresses and 480 improved the plants resistance to abiotic stresses. The potential functions of BvAQPs were 481 predicted and discussed based on NPA motifs, ar/R selectivity filter, Froger's positions and SDP 482 positions analysis. This study provide a useful resource for identifying and characterizing 483 BvAQPs and a base for breeding and genetic engineering of sugar beet.

\section{Acknowledgments}

The authors appreciate those contributors who make the sugar beet genome and transcriptome data accessible in public databases.

\section{Reference}

Amodeo G, Dorr R, Vallejo A, Sutka M, and Parisi M. 1999. Radial and axial water transport in the sugar beet storage root. Journal of Experimental Botany 50(333): 509-516.

DOI:10.1093/jxb/50.333.509

Anderberg HI, Kjellbom P, and Johanson U. 2012. Annotation of Selaginella moellendorffii major intrinsic proteins and the evolution of the protein family in terrestrial plants. Frontiers in Plant Science 3. Artn 33

DOI 10.3389/fpls.2012.00033

Ariani A, and Gepts P. 2015. Genome-wide identification and characterization of aquaporin gene family in common bean (Phaseolus vulgaris L.). Molecular Genetics and Genomics 290:1771-1785.

DOI 10.1007/s00438-015-1038-2

Bansal A, and Sankararamakrishnan R. 2007. Homology modeling of major intrinsic proteins in 
503

504

505

506

507

508

509

510

511

512

513

514

515

516

517

518

519

520

521

522

523

524

525

526

527

528

529

530

531

532

533

534

535

536

537

538

539

540

541

542

543

rice, maize and Arabidopsis: comparative analysis of transmembrane helix association and aromatic/arginine selectivity filters. BMC Structural Biology 7:1-17.

DOI 10.1186/1472-6807-7-27

Baranwal VK, Negi N, and Khurana P. 2016. Genome-wide identification and structural, functional and evolutionary analysis of WRKY components of Mulberry. Scientific Reports 6.

DOI 10.1038/srep30794

Bellati J, Alleva K, Soto G, Vitali V, Jozefkowicz C, Amodeo G. 2010. Intracellular pH sensing is altered by plasma membrane PIP aquaporin co-expression. Plant Molecular Biology 74 (1) :105-118

DOI: $10.1007 / \mathrm{s} 11103-010-9658-8$

Bove J, Kim CY, Gibson CA, and Assmann SM. 2008. Characterization of wound-responsive RNAbinding proteins and their splice variants in Arabidopsis. Plant Molecular Biology 67:7188.

DOI 10.1007/s11103-008-9302-z

Bowers JE, Chapman BA, Rong J, and Paterson AH. 2003. Unravelling angiosperm genome evolution by phylogenetic analysis of chromosomal duplication events. Nature 422:433438.

DOI 10.1038/nature01521

Chaumont F, Barrieu F, Wojcik E, Chrispeels MJ, and Jung R. 2001. Aquaporins constitute a large and highly divergent protein family in maize. Plant Physiology 125:1206-1215.

DOI 10.1104/pp.125.3.1206

Cheng F, Mandáková T, Wu J, Xie Q, Lysak MA, and Wang X. 2013. Deciphering the diploid ancestral genome of the mesohexaploid Brassica rapa. Plant Cell 25:1541-1554.

DOI 10.1105/tpc.113.110486

Chiba Y, Mitani N, Yamaji N, and Ma JF. 2009. HvLsi1 is a silicon influx transporter in barley. Plant Journal 57:810-818.

DOI 10.1111/j.1365-313X.2008.03728.x

Danielson JAH, and Johanson U. 2008. Unexpected complexity of the aquaporin gene family in the moss Physcomitrella patens. BMC Plant Biology 8. Artn 45

DOI 10.1186/1471-2229-8-45

Dohm JC, Minoche AE, Holtgräwe D, Capellagutiérrez S, Zakrzewski F, Tafer H, Rupp O, Sörensen TR, Stracke R, and Reinhardt R. 2014. The genome of the recently domesticated crop plant sugar beet (Beta vulgaris). Nature 505:546-549.

DOI 10.1038/nature12817

Doyle JJ, Paterson AH, Soltis DE, and Wendel JF. 2008. Evolutionary genetics of genome merger and doubling in plants. Genetics 42:443-461.

DOI 10.1146/annurev.genet.42.110807.091524

Fitzpatrick KL, and Reid RJ. 2009. The involvement of aquaglyceroporins in transport of boron in barley roots. Plant Cell \& Environment 32:1357-1365.

DOI 10.1111/j.1365-3040.2009.02003.x 
544 Froger A, Tallur B, Thomas D, and Delamarche C. 1998. Prediction of functional residues in

545

546

547

548

549

550

551

552

553

554

555

556

557

558

559

560

561

562

563

564

565

566

567

568

569

570

571

572

573

574

575

576

577

578

579

580

581

582

583

584 water channels and related proteins. Protein Science 7:1458-1468.

DOI 10.1002/pro.5560070623

Gao Z, He X, Zhao B, Zhou C, Liang Y, Ge R, Shen Y, and Huang Z. 2010. Overexpressing a putative aquaporin gene from wheat, TaNIP, enhances salt tolerance in transgenic Arabidopsis. Plant \& Cell Physiology 51:767-775.

DOI 10.1093/pcp/pcq036

Gassmann W. 2008. Alternative splicing in plant defense. Current Topics in Microbiology \& Immunology 326:219-234.

Gentleman RC, Carey VJ, Bates DM, Bolstad B, Dettling M, Dudoit S, Ellis B, Gautier L, Ge Y, and Gentry J. 2004. Bioconductor: open software development for computational biology and bioinformatics. Genome Biology 5:1-16.

DOI 10.1186/gb-2004-5-10-r80

Gomes D, Agasse A, Thiébaud P, Delrot S, Gerós H, and Chaumont F. 2009. Aquaporins are multifunctional water and solute transporters highly divergent in living organisms. Biochimica Et Biophysica Acta 1788:1213-1228.

DOI 10.1016/j.bbamem.2009.03.009

Gu Z, Cavalcanti A, Chen FC, Bouman P, and Li WH. 2002. Extent of gene duplication in the genomes of drosophila, nematode, and yeast. Molecular Biology and Evolution 19:256262.

DOI https://doi.org/10.1093/oxfordjournals.molbev.a004079

Gupta A, and R S. 2009. Genome-wide analysis of major intrinsic proteins in the tree plant Populus trichocarpa: characterization of XIP subfamily of aquaporins from evolutionary perspective. BMC Plant Biology 9:134.

DOI 10.1186/1471-2229-9-134

Gupta AB, and Sankararamakrishnan R. 2009. Gupta AB, Sankararamakrishnan R. 2009. Genome-wide analysis of major intrinsic proteins in the tree plant Populus trichocarpa: characterization of XIP subfamily of aquaporins from evolutionary perspective. BMC Plant Biol. 9. 9.

DOI 10.1186/1471-2229-9-134

He H, Dong Q, Shao Y, Jiang H, Zhu S, Cheng B, and Xiang Y. 2012. Genome-wide survey and characterization of the WRKY gene family in Populus trichocarpa. Plant Cell Reports 31:1199-1217.

DOI 10.1007/s00299-012-1241-0

Heinen RB, and Chaumont F. 2009. Role of aquaporins in leaf physiology. Journal of Experimental Botany 60:2971-2985.

DOI 10.1093/jxb/erp171

Hove RM, and Bhave M. 2011. Plant aquaporins with non-aqua functions: deciphering the signature sequences. Plant Molecular Biology 75:413-430.

DOI 10.1007/s11103-011-9737-5

$\mathrm{Hu} \mathrm{W.} \mathrm{2012.} \mathrm{Overexpression} \mathrm{of} \mathrm{a} \mathrm{wheat} \mathrm{aquaporin} \mathrm{gene,} \mathrm{TaAQP8,} \mathrm{enhances} \mathrm{salt} \mathrm{stress}$ 
585

586

587

588

589

590

591

592

593

594

595

596

597

598

599

600

601

602

603

604

605

606

607

608

609

610

611

612

613

614

615

616

617

618

619

620

621

622

623

624

625

tolerance in transgenic tobacco. Plant \& Cell Physiology 53:2127-2141.

DOI 10.1093/pcp/pcs154

Jang YH, Lee JH, Park HY, Kim SK, Lee BY, Suh MC, and Kim JK. 2009. OsFCA transcripts show more complex alternative processing patterns than its Arabidopsis counterparts. Journal of Plant Biology 52:161-166. 10.1007/s12374-009-9018-x

DOI 10.1007/s12374-009-9018-x

Johanson $U$, and Kjellbom P. 2001. The complete set of genes encoding major intrinsic proteins in Arabidopsis provides a framework for a new nomenclature for major intrinsic proteins in plants. Plant Physiol. Plant Physiology 126:1358-1369.

DOI 10.1104/pp.126.4.1358

Johnson KD, Herman EM, and Chrispeels MJ. 1989. An abundant, highly conserved tonoplast protein in seeds. Plant Physiology 91:1006-1013.

DOI 10.1104/pp.91.3.1006

Jozefkowicz C, Rosi P, Sigaut L, Soto G, Pietrasanta LI, Amodeo G, Alleva K. 2013. Loop A is critical for the functional interaction of two Beta vulgaris PIP aquaporins. PLoS One 8(3):e57993.

DOI: 10.1371/journal.pone.0057993

Jozefkowicz C, Sigaut L, Scochera F, Soto G, Ayub N, Pietrasanta LI, Amodeo G, González Flecha $\mathrm{FL}$, Alleva K. 2015. PIP water transport and its $\mathrm{pH}$ dependence are regulated by tetramer stoichiometry. Biophysical Journal 110 (6):1312-1321

DOI: 10.1016/j.bpj.2016.01.026

Liu QP, and Zhu ZJ. 2010. Functional divergence of the NIP III subgroup proteins involved altered selective constraints and positive selection. BMC Plant Biology 10. Artn 256

DOI 10.1186/1471-2229-10-256

Ma JF, Tamai K, Yamaji N, Mitani N, Konishi S, Katsuhara M, Ishiguro M, Murata Y, and Yano M. 2006. A silicon transporter in rice. Nature 440:688-691. 10.1038/nature04590

DOI 10.1038/nature04590

Ma JF, Yamaji N, Mitani N, Xu XY, Su YH, McGrath SP, and Zhao FJ. 2008. Transporters of arsenite in rice and their role in arsenic accumulation in rice grain. Proceedings of the National Academy of Sciences of the United States of America 105:9931-9935. $10.1073 /$ pnas.0802361105

DOI 10.1073/pnas.0802361105

Maurel C, Boursiac Y, Luu D T, Verdoucq L. 2015. Aquaporins in Plants. Physiological Reviews. 95(4):1321.

DOI 10.1152/physrev.00008.2015

Maurel C, Santoni V, Luu DT, Wudick MM, and Verdoucq L. 2009. The cellular dynamics of plant aquaporin expression and functions. Current Opinion in Plant Biology 12:690-698.

DOI 10.1016/j.pbi.2009.09.002

Maurel C, Verdoucq L, Luu DT, and Santoni V. 2008. Plant aquaporins: membrane channels with multiple Integrated functions. Plant Biology 59:595-624.

DOI 10.1146/annurev.arplant.59.032607.092734 
626 Minoche AE, Dohm JC, Schneider J, Holtgräwe D, Viehöver P, Montfort M, Sörensen TR,

627

628

629

630

631

632

633

634

635

636

637

638

639

640

641

642

643

644

645

646

647

648

649

650

651

652

653

654

655

656

657

658

659

660

661

662

663

664

665

666

Weisshaar B, and Himmelbauer H. 2015. Exploiting single-molecule transcript sequencing for eukaryotic gene prediction. Genome Biology 16:1-13.

DOI 10.1186/s13059-015-0729-7

Mitani-Ueno N, Yamaji N, Zhao FJ, and Ma JF. 2011. The aromatic/arginine selectivity filter of NIP aquaporins plays a critical role in substrate selectivity for silicon, boron, and arsenic. Journal of Experimental Botany 62:4391-4398.

DOI 10.1093/jxb/err158

Mitani N, Yamaji N, and Ma JF. 2008. Characterization of substrate specificity of a rice silicon transporter, Lsi1. Pflugers Archiv-European Journal of Physiology 456:679-686. 10.1007/s00424-007-0408-y

DOI 10.1007/s00424-007-0408-y

Morita S, Sugiyama S, Tateishi A, and Satoh S. 2017. Identification and Characterization of Plasma Membrane Intrinsic Protein (PIP) Aquaporin Genes in Petals of Opening Carnation Flowers. Horticulture Journal.

DOI 10.2503/hortj.MI-127

Nguyen MX, Moon S, and Jung KH. 2013. Genome-wide expression analysis of rice aquaporin genes and development of a functional gene network mediated by aquaporin expression in roots. Planta 238:669-681.

DOI 10.1007/s00425-013-1918-9

Prado K, and Maurel C. 2013. Regulation of leaf hydraulics: from molecular to whole plant levels. Frontiers in Plant Science 4:58-60.

DOI 10.3389/fpls.2013.00255

Quigley F. 2001. From genome to function: the Arabidopsis aquaporins. Genome Biology 3:RESEARCH0001.

DOI 10.1186/gb-2001-3-1-research0001

Reddy ASN, and Golovkin MV. 2010. Nuclear pre-mRNA Processing in Plants. Springer Berlin 326.

DOI 10.1016/S1040-8428(13)70160-4

Reuscher S, Akiyama M, Mori C, Aoki K, Shibata D, and Shiratake K. 2013a. Genome-Wide Identification and Expression Analysis of Aquaporins in Tomato. Plos One 8:e79052.

DOI 10.1371/journal.pone.0079052

Reuscher S, Akiyama M, Mori C, Aoki K, Shibata D, and Shiratake K. 2013b. Genome-wide identification and expression analysis of aquaporins in tomato. Plos One 8:615-629.

DOI 10.1371/journal.pone.0079052

Sade N. 2010. The role of tobacco Aquaporin1 in improving water use efficiency, hydraulic conductivity, and yield production under salt stress. Plant Physiology 152:245-254.

DOI 10.1104/pp.109.145854

Skorupakłaput M, Szczepanek J, Kurnik K, Tretyn A, and Tyburski J. 2015. The expression patterns of plasma membrane aquaporins in leaves of sugar beet and its halophyte relative, Beta vulgaris ssp. maritima, in response to salt stress. Biologia 70 (4):467-477 
667

668

669

670

671

672

673

674

675

676

677

678

679

680

681

682

683

684

685

686

687

688

689

690

691

692

693

694

695

696

697

698

699

700

701

702

703

704

705

706

707

DOI:10.1515/biolog-2015-0056

Sreedharan S, Shekhawat UKS, and Ganapathi TR. 2015. Constitutive and stress-inducible overexpression of a native aquaporin gene (MusaPIP2;6) in transgenic banana plants signals its pivotal role in salt tolerance. Plant Molecular Biology 88:41-52.

DOI 10.1007/s11103-015-0305-2

Stracke R, Holtgräwe D, Schneider J, Pucker B, Sörensen TR, and Weisshaar B. 2014. Genomewide identification and characterisation of R2R3-MYB genes in sugar beet ( Beta vulgaris ). BMC Plant Biology 14:1-17.

DOI 10.1186/s12870-014-0249-8

Tao P, Zhong X, Li B, Wang W, Yue Z, Lei J, Guo W, and Huang X. 2014. Genome-wide identification and characterization of aquaporin genes (AQPs) in Chinese cabbage (Brassica rapa ssp. pekinensis). Molecular Genetics and Genomics 289:1131-1145.

DOI 10.1007/s00438-014-0874-9

Uehlein N, and Kaldenhoff R. 2008. Aquaporins and plant leaf movements. Annals of Botany 101:1-4.

DOI $10.1093 / \mathrm{aob} / \mathrm{mcm} 278$

Venkatesh J, Yu JW, and Park SW. 2013. Genome-wide analysis and expression profiling of the Solanum tuberosum aquaporins. Plant Physiology \& Biochemistry 73C:392-404.

DOI 10.1016/j.plaphy.2013.10.025

Wudick MM, and Maurel C. 2009. A look inside: localization patterns and functions of intracellular plant aquaporins. New Phytologist 184:289-302.

DOI 10.1111/j.1469-8137.2009.02985.x

Xu Y, Hu W, Liu J, Zhang J, Jia C, Miao H, Xu B, and Jin Z. 2014. A banana aquaporin gene, MaPIP1;1, is involved in tolerance to drought and salt stresses. BMC Plant Biology 14:59.

DOI 10.1186/1471-2229-14-59

Yamaji N, and Ma JF. 2009. A transporter at the node responsible for intervascular transfer of silicon in rice. Plant Cell 21:2878-2883. 10.1105/tpc.109.069831

DOI 10.1105/tpc.109.069831

Yamaji N, Mitatni N, and Ma JF. 2008. A transporter regulating silicon distribution in rice shoots. Plant Cell 20:1381-1389. 10.1105/tpc.108.059311

DOI 10.1105/tpc.108.059311

Yu J, and Yang H. 2002. A draft sequence of the rice genome (Oryza sativa L. ssp. indica). Science 296:1937-1942.

DOI 10.1126/science.1068037

Zhang DY, Ali Z, Wang CB, Xu L, Yi JX, Xu ZL, Liu XQ, He XL, Huang YH, and Khan IA. 2013. Genome-wide sequence characterization and expression analysis of major intrinsic proteins in soybean (Glycine max L.). Plos One 8:-.

DOI 10.1371/journal.pone.0056312

Zhi Z, Gong J, Feng A, Xie G, Wang J, Mo Y, and Yang L. 2015. Genome-wide identification of rubber tree (Hevea brasiliensis Muell. Arg.) aquaporin genes and their response to 
708 ethephon stimulation in the laticifer, a rubber-producing tissue. BMC Genomics 16:1-18.

709 DOI 10.1186/s12864-015-2152-6

710 Zhou S, Hu W, Deng X, Ma Z, Chen L, Huang C, Wang C, Wang J, He Y, and Yang G. 2012.

711 Overexpression of the wheat aquaporin gene, TaAQP7, enhances drought tolerance in $712 \quad$ transgenic tobacco. Plos One 7:e52439.

713 DOI 10.1371/journal.pone.0052439

714 Zou Z, Gong J, Huang Q, Mo Y, Yang L, and Xie G. 2015. Gene structures, evolution, classification

715 and expression profiles of the aquaporin gene family in castor bean (Ricinus communis

716 L.). Plos One 10:e0141022.

717 DOI 10.1371/journal.pone.0141022

718 